\title{
Life cycle energy efficiency in building structures: A review of current developments and future outlooks based on BIM capabilities
}

\author{
Stathis Eleftheriadis ${ }^{\mathrm{a}, \mathrm{c}, *}$, Dejan Mumovic ${ }^{\mathrm{a}}$, Paul Greening $^{\mathrm{b}}$ \\ ${ }^{a} U C L$ Institute for Environmental Design and Engineering, University College London, WC1H 0NN, United Kingdom \\ ${ }^{b}$ Faculty of Engineering, Environment and Computing, Coventry University, CV1 5FB, United Kingdom \\ 'Price \& Myers Consulting Engineers, 37 Alfred Place, WC1E 7DP, London, United Kingdom \\ *Corresponding author at Price \& Myers Consulting Engineers, 37 Alfred Place, WC1E 7DP, London, United Kingdom. \\ Tel: +44(0)7955240317, E-mail address: stathiseleftheriadis@gmail.com
}

\begin{abstract}
The continuous developments of Building Information Modelling (BIM) in Architecture, Engineering and Construction (AEC) industry supported by the advancements in material resourcing and construction processes could offer engineers the essential decision-making procedures to leverage the raising demands for sustainable structural designs. This article brings together the theory of Life Cycle Assessment (LCA) and the capabilities of BIM to survey the current developments in the energy efficiency of structural systems. In addition, the article explores the engineering dimensions of common decision-making procedures within BIM systems including optimisation methods, buildability limitations and safety and code compliance checks. The research presents critical expositions in both the engineering and sustainable energy domains. The article then argues that future innovations in the sustainable decision-making of buildings' structures would require BIM-integrated workflows in order to facilitate the conflicting nature of both energy efficient and engineering performance indexes. Finally, the study puts forward a series of research guidelines for a consolidated decision paradigm that utilises the capabilities of BIM within the engineering and sustainable energy domains in a synergistic manner.
\end{abstract}

Keywords: BIM, LCA, Energy efficiency, Sustainable structures, Building systems

\section{Contents}

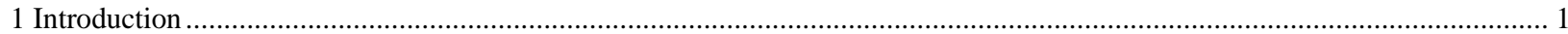

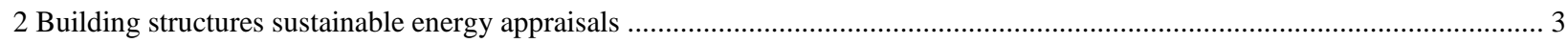

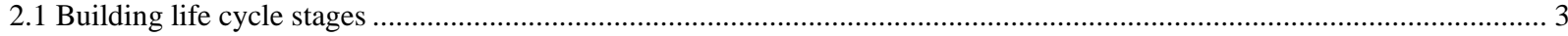

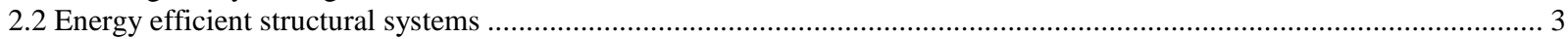

2.3 Discrepancies between operational and embodied energy analysis...................................................................... 4

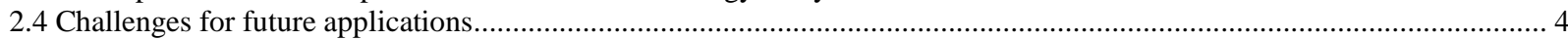

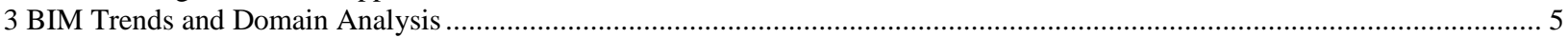

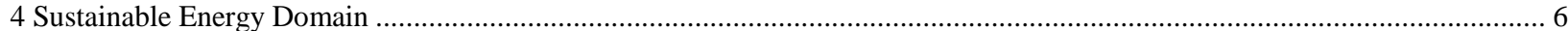

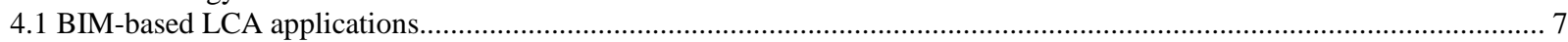

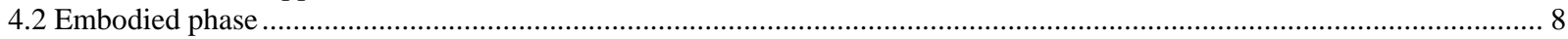

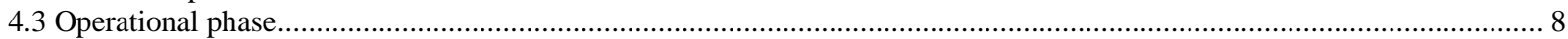

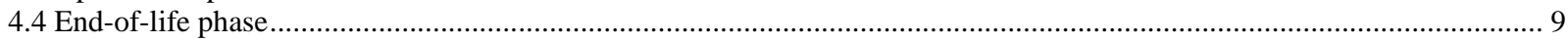

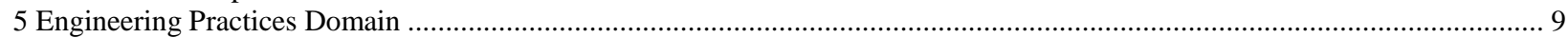

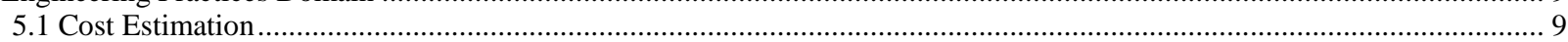

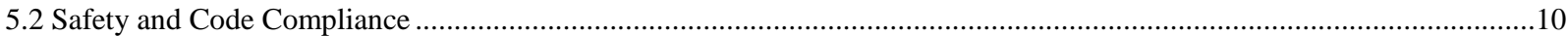

5.3 Buildability and construction processes

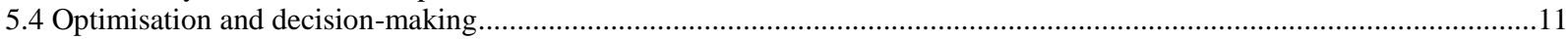

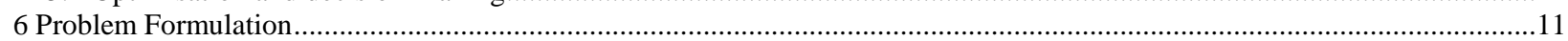

7 Towards consolidated decision frameworks for structural and sustainability domains ....................................................12

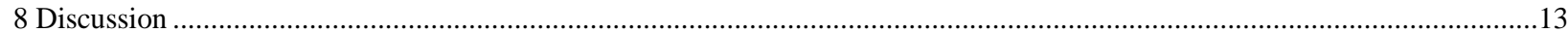

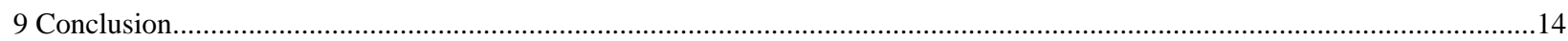

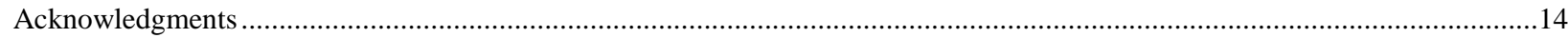

\section{Introduction}

During the last 20 years, Life Cycle Assessment (LCA) has been extensively used as a sustainable methodology that has the potential to quantify and to reduce the environmental impacts and the energy use of building systems $[1,2,3$, 4]. In structural engineering besides LCA, other energy efficient strategies often involve the reduction of materials' use and production energy as well as the increase of structural systems reuse rates $[5,6]$. Because there is no single approach that can address all the issues of sustainable structural systems, it is crucial to understand the flow of interactions between materials, components, and processes within the building life-cycle in order to successfully meet national and global environmental emissions' targets [7], and in order to optimise the energy balance between the various building components [8]. Some of the challenges structural engineers are still facing today when implementing sustainable methodologies include: 1) Cost reductions (Economic level), 2) Convincing clients of the potential benefits (Industrial level), 3) Educating stakeholders regarding the available design alternatives (Educational level), and 4) Ensuring that sustainable solutions don't compromise the structural characteristics (Performance level) [9]. Furthermore, the limited applications of sustainable environmental approaches in building structures are often attributed to the lack of reliable and user-friendly computational tools [10]. 
Building Information Modelling (BIM) is defined as "a set of interacting policies, processes and technologies generating a methodology to manage the essential building design and project data in digital format throughout the building's life-cycle" [11]. BIM is seen as a consolidated model, which often can be used to store and communicate geometric, spatial relationships, geographic information, quantities and properties of various building components, cost estimates, material inventories and project schedules [12, 13]. In building projects where several stakeholders are involved in the decision procedures, BIM could be implemented to enhance information exchange and teams' collaboration at design and construction phases $[14,15,16]$. Furthermore, the use of BIM has the potential to revolutionise the way environmental impact and energy models are integrated within the building systems [17, 18]. BIM has been extensively used as a platform that enhances the design team's capabilities to coordinate building documentation, to monitor construction works and to manage facilities during the different operational phases of a building in an integrated and systematic way [18]. Research activity has begun to develop new BIM applications that address a range of sustainability related issues [19, 20]: the assessment of environmental impacts [21], waste management $[22,23]$, environmental design guidance $[24,25,26,27]$ and government strategy for carbon reductions in both the current and the future building stock [28]. However, further studies on the integration of BIM with sustainable and green building strategies are required in order to maximise the environmental and energy benefits during the various life cycle stages [29, 30].

Weisenberger [31] has raised the question on how structural engineers can influence the development of sustainable building designs focusing on the "collective design and construction consciousness". In this collective decision process, structural engineers could utilise BIM-integrated applications in order to look beyond the material selection and focus on design decisions that optimise the material performance of buildings in a holistic manner. In structural systems the advantages as well as the limitations of BIM integration have been reported by Solnosky [32], whilst Nawari et al. [33] have suggested that BIM integrated structural analysis will allow engineering students and practitioners to develop a finer understanding of the various structural concepts. The next generation of BIM-based structural modelling platforms would include Design Authoring Modelling (Code checking and feedback), Analysis \& Design Modelling (Simulations), Detailing/Component Modelling (Buildability), Fabrication Modelling, and Construction Application Modelling (Coordination) [33]. In addition, integrated structural design and construction processes within BIM can be organised in the three phases that include: 1) Concept design, 2) System design, and 3) Component design [34].

Traditionally, the main reasons behind the lack of embedded and sustainable decision-making practices in building structural systems have been credited to the scarce or the inefficiency of policy requirements associated with the structures' sustainable performance and the confusion amongst many practitioners regarding effective energy efficient structural solutions [35]. In practice, the involvement of structural engineers in the selection of building sustainable and low energy strategies is commonly neglected [36]. Other constraints that restrict the application of sustainable methodologies in structural engineering practice include [5]:1) The additional design and analysis time that is required to conduct detailed optimisation studies at material and system level, 2) The vagueness of the relationship between the structural systems and the materials' production energy, 3) The lack of association between embodied energy of materials with structural performance, 4) The uncertainty and reluctance around the overall LCA capabilities, 5) The absence of systematic reuse mechanisms to accurately model and inspect the versatility building structural systems.

The authors envisage the current BIM developments as an opportunity for structural engineers to radically shift the existing design and delivery procedures of energy efficient structures by expanding the engineering domain into the sustainable performance domain and by creating a synergistic decision space that operates under a common BIM policy. The raising concerns for climate resilient buildings are expected to reinforce the requirements for novel decision-making paradigms in building structures that will augment the traditional engineering performance indexes (cost, safety and buildability) with sustainable components (energy use, resources depletion, emissions and waste). The research offers potential advances that could emerge in the field of structural engineering from the integration of BIM with sustainability assessments and particularly with life cycle energy components.

The remainder of this article is organised as follows. In Section 2, the preliminary appraisals of traditional energy efficiency and sustainability models in structural engineering are analysed and supported by main findings. In Section 3 the general methodological framework of the study is elaborated, which is structured around two domains: engineering and sustainability domains. Section 4 investigates the applications of BIM techniques in the evaluation of life cycle environmental and energy impacts including materials analysis, structural systems' comparisons and building construction relationships. In Section 5 the relevant fields of the engineering domain such as cost estimation, constructability and safety are explicated. Section 6 presents the general principles of the problem formulation, whilst the proposed guidelines for a consolidated decision model within BIM are specified in Section 7. Practical applications and extensions are discussed in section 8. The paper closes with conclusions in section 9 . 


\section{Building structures sustainable energy appraisals}

LCA approaches have been used in buildings to inform sustainable and energy efficient decisions by examining their environmental impacts [37]. LCA is an analytical evaluation procedure that quantifies the potential environmental impacts of products, processes or systems during their lifetime and it covers the stages from raw material extraction and production to operation and end-of-life [38]. The LCA methodology consists of four distinct phases: Goal and Scope Definition, Life-cycle Inventory (LCI), Life-cycle Impact Assessment (LCIA) and Interpretation [39]. The international standard ISO 14040 [38] defines LCA as "a technique for assessing the environmental aspects and potential impacts associated with a product, by: compiling an inventory of relevant inputs and outputs of a product system; evaluating the potential environmental impacts; and interpreting the results of the inventory analysis and impact assessment phases".

\subsection{Building life cycle stages}

Energy efficiency measures in buildings focus on the environmental impacts of the: 1) Embodied phase, 2) Operational phase and 3) End-of-life phase $[40,41]$. The embodied phase takes into account the impacts from the processes associated with the construction of a building including: material acquisition, transportation to site and construction activities. Embodied impacts can further sub-divided into two parts: the initial and the recurring impacts [7]. The initial embodied impacts of a building represent the type of materials used, the primary energy sources, the transportation to the site and the preliminary construction processes. The recurring embodied impacts are related to maintenance and replacement of materials or components during the entire lifetime of a building [36, 42, 43, 44]. The operational stage of an LCA is linked to the energy emissions during the occupation phase of a building and usually covers a significant proportion of its total life cycle emissions. It includes all the impacts associated with the building's systems such as heating, cooling, lighting, ventilation, equipment use, etc. [36, 45, 46]. The operational impacts accumulate over time and they can be significantly influenced by the occupants' pattern of energy use and systems' efficiencies [7]. Finally, the end-of-life stage of an LCA includes the impacts associated with the demolition, transportation of waste materials to landfill and recycling or re-use processes [36]. A building's total life-cycle energy emissions are the sum of the embodied emissions, the operational emissions and the emissions associated with the end-of-life $[36,45]$.

\subsection{Energy efficient structural systems}

Our intention is not to provide an extensive review of LCA theory in building systems, as detailed reviews on the topic can be found in previous literature $[47,36,2]$. LCA has a great potential to drive energy efficient decisions specifically when applied early in the design process especially in the selection of materials and systems, in the assessment of design alternatives, in the development of the construction programme, etc. In this section the capabilities of LCA as a decision-making methodology in building structures are explored by reviewing several practical examples from the literature. LCA applications can be divided in two main categories depending on whether the use/operational phase is included in the study. Ortiz et al. [47] have found that $60 \%$ of the studies they reviewed use LCA only for the appraisal of building and material components. On the other hand, only $40 \%$ of the cases include a whole life analysis. We have found that in building structures, the application of LCA could be organised in two subsequent levels depending on the whether the structural system is studied in isolation (System Level) or as part a whole building assessment (Building level). At system level, LCA is being used to compare primarily the embodied energy and emissions of different structural or material alternatives. At building level, structural alternatives are compared as part of full-building LCA including both the operational and the embodied phases. From the analysis of LCA applications in building structures four main categories have been recognised: 1) Structural Frames, 2) Structural Walls, 3) Structural Floors and 4) Material Properties. Interestingly enough in the cases where the structural frame of a building is assessed the application of the LCA was conducted at building level. On the other hand, in all of the other 3 categories it becomes evident that the embodied energy and emissions are the main quantitative measures the researchers has used. Table 1 summarises the findings.

Table 1 Analysis of traditional LCA applications in building structures

\begin{tabular}{|c|c|c|c|}
\hline Category & Description & Level & Reference \\
\hline \multirow{6}{*}{$\begin{array}{l}\text { Structural } \\
\text { Frames }\end{array}$} & Concrete & Building Level & Dimoudi \& Tompa [48] \\
\hline & Steel and concrete & Building Level & Xing et al. [49] \\
\hline & Concrete and Timber & Building Level & $\begin{array}{l}\text { Gustavsson \& Sathre [50] } \\
\text { Hossaini et al. [51] }\end{array}$ \\
\hline & Concrete, steel and timber & Building Level & $\begin{array}{l}\text { John et al. [52] } \\
\text { Perez et al. [3] }\end{array}$ \\
\hline & $\begin{array}{l}\text { Multiple: Cross Laminated Timber, Reinforced Concrete, } \\
\text { Aircrete, Brick, Steel, Light Weight Timber }\end{array}$ & Building Level & Takano et al. [8] \\
\hline & Pre-cast panels and reinforced concrete & System Level & Omar et al [53] \\
\hline
\end{tabular}


Multiple: Concrete block, insulated concrete, poured-in-place concrete, two types of traditional wood frames, steel stud and structural insulated panels

Structural Post-tensioned concrete and reinforced concrete

Floors

\section{Concrete floors}

Multiple: Steel composite floors, Reinforced concrete floors and 4xlightweight floors

Material

Properties
System Level

Building Level

System Level

Kahhat et al. [55]

Miller et al. [56]

Miller et al. [57]

Miller et al. [58]

System Level

Hajek [59]

Fiala \& Hajek [60]

System Level Foraboschi et al. [61]

System Level

Tae et al. [62]

System Level Lee et al. [63]

Concrete strength and carbonation

\subsection{Discrepancies between operational and embodied energy analysis}

Traditionally decision-making in building design have focused on energy measures that address the operational phase, as the main driver has been the increasing policies related to energy use in buildings [64]. In the past, research efforts have analysed the impacts of different building materials in the energy performance leaving out the impacts of the other life cycle phases [65]. In addition, there is no policy in place that regulates the amount of embodied impacts or other non-operational impacts of a building. However, moving towards stricter energy policies and Zero Energy Buildings (ZEB), improvements of the embodied energy phase are expected to become more and more significant as the operational energy will decrease $[35,64,65]$. Therefore, as the other life cycle phases become more important the need for systematic analysis of embodied and operational impacts as well as the optimisation of embodied impacts will become imperative [65]. Dixit et al. [66] in their review, examined studies published before 2000 that focus on the embodied energy of building materials (production phase, on-site delivery, construction and assembly on-site, renovation and final demolition stages). Great inconsistencies in the assessment of the embodied energy of different construction types in residential and commercial buildings have been observed (Figure 1). Their study suggests that the interpretation of the embodied energy within the existing LCA methods is quite unclear and they expect that a common protocol for embodied energy measurements within the industry will address this issue in the future [66]. Furthermore, the relationships between the embodied and operational energy emissions have also begun to attract attention amongst researchers. More than 20 LCA studies at building level between 1996 and 2012 have been examined by Miller \& Doh [35] (Figure 2). Significant variations occur between the distribution of embodied and operational energy estimations for different building structures (particularly between reinforced concrete and steel structures). Despite Dixit et al's [66] and Miller \& Doh's [35] extensive work on this area, standardised systems for the environmental assessment of building structures that address 1) the discrepancies between the embodied and operational energy and 2) the limited consideration of energy efficient strategies by structural engineers practitioners are still underdeveloped.

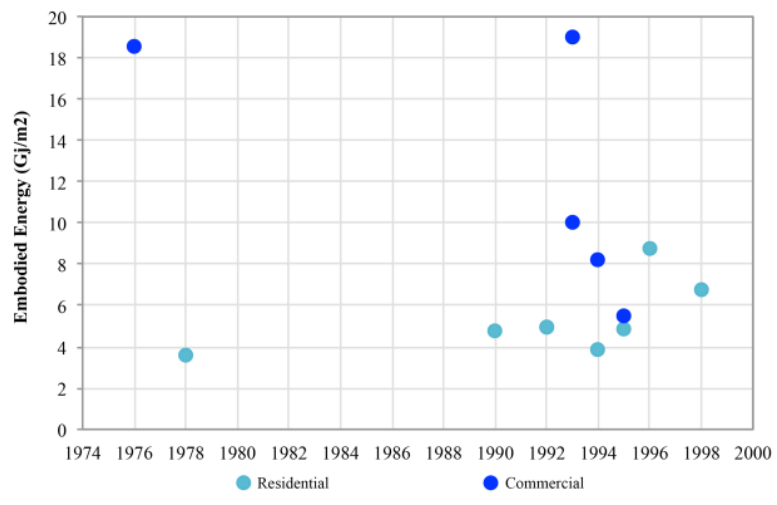

Figure 1 Embodied energy distribution, adapted from [66]

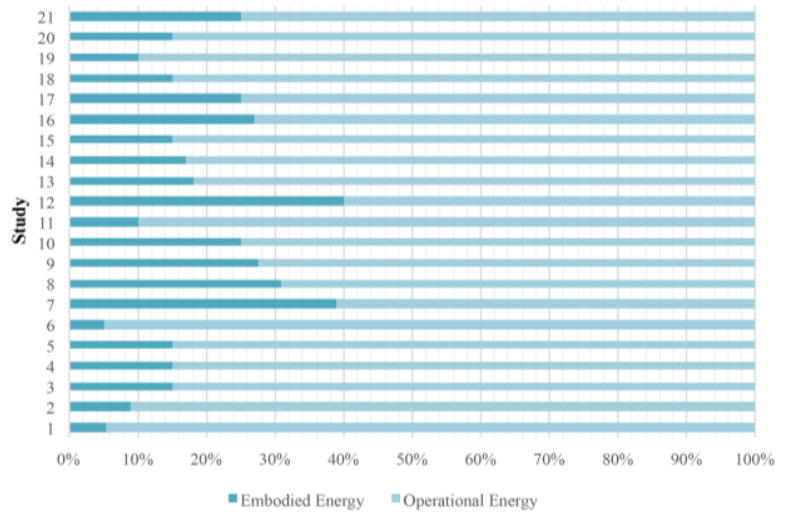

Figure 2 Life cycle energy distribution, adapted from [35]

\subsection{Challenges for future applications}

In addition to the disparities observed at practical level in the previous section other inherent limitations of LCA models that restrict their implementation during the early decision-making in buildings structural systems are:

1. It is a time-consuming procedure and it requires a certain level of familiarisation with the main concepts especially when it is applied to buildings $[67,68]$,

2. The selection of the appropriate environmental impact category (energy, waste, carbon emissions) can be challenging [69], 
3. It involves significant amount of data early in the decision process, whilst their quality and transparency are critical for the final assessment [67],

4. Building components and systems are not standardised and thus whole building assessments involve an increased level of uncertain factors (life span, maintenance and use patterns, future use) [68],

5. It is often applied at a later phase of a project for certification purposes and not as decision-making process early in the design development [67],

6. There is a lack of consensus on the LCA methodologies. Some of the common methods are ENCORD, GHG Protocol, ISO 14064, PAS 2050, IPCC National Greenhouse Gas List Guide [70]

Latest research approaches particularly focus on the improvements of LCA data quality and the mitigation of uncertainties when obtaining inventory information. For further reading on the LCI databases and LCA software the authors suggest the work by Moncaster \& Song [68]. Input-output LCA methods (IO-LCA) are suitable for the analysis of basic construction materials utilising data from a nationwide perspective using a country's input-output tables (IOTs) [71]. However, IO-LCA is not suitable for individual buildings due to the complexities associated with construction projects where hybrid LCA methods are more appropriate [72]. Hybrid methods combine input-output models with more reliable and site-specific data. When actual data are not available, other novel LCA approaches associated with the specification of robust LCI inventories include Bayesian theory and agentbased model (ABM) [73], Data Quality Indicator (DQI) with Monte-Carlo sensitivity analysis [74], Path Exchange method [75], System Dynamics [76], Semantic Approaches [77] to name a few. Overall, future developments in this field will require integrated cross-disciplinary models of life cycle environmental and energy analysis in order to support new policies, to harmonise with existing assessment approaches, to consolidate decision-making processes and to embrace the advancements in the field of computational and information technologies such as data mining, artificial intelligence and optimisation [76].

\section{BIM Trends and Domain Analysis}

BIM models can be utilised to enhance the delivery of building design as drawings, procurement details, submittal processes and other specifications can easily be interrelated: data generated by BIM can be extracted and analysed to produce information, which thereafter is used to make decisions and to improve design processes. BIM can also be used as a platform that enhances the team's capabilities to coordinate the design procedure, to monitor the construction works and to manage the facilities during the projects' different phases within an integrated approach. BIM has also been used as a novel approach to perform energy, daylighting, and structural analyses along with cost estimation. It has been sourced as a building construction's environmental impacts assessment and monitoring method. Moreover, BIM-based approaches have been forming a part of the sustainability rating systems. Thus, the BIM integration with other simulation tools can significantly contribute to the sustainability assessments within the building sector. In order to review the capabilities of sustainable and energy efficient decision-making models in building structures this research investigates practical BIM-based applications and advancements within two knowledge domains: 1) Sustainable energy domain and 2) Structural Engineering processes domain. The sustainability domain is organised around life cycle energy processes whereas the engineering domain is structured around common engineering variables that include cost, constructability, safety, etc. The purpose of this classification aims to recognise potential constraints within the current systems as well as highlight prospective links between the subsequent attributes of each field that will help establish consolidated engineering-sustainability paradigms in building structures. Figure 3 shows the conceptual representation of the study.

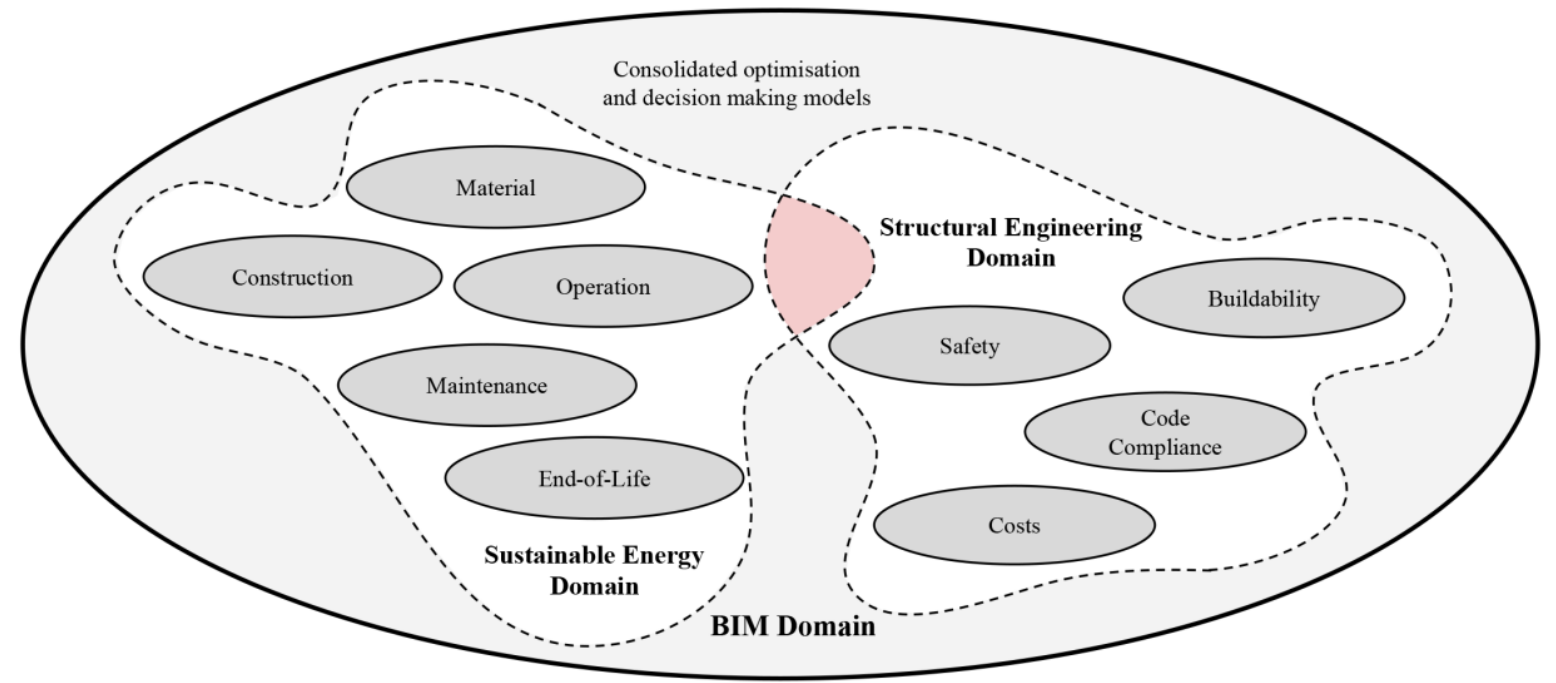

Figure 3 Domain fields of the study 
In order to identify the current trends in this field a systematic research was performed using peer-reviewed literature by searching online databases of relevant journals. The period of research covers studies published between 2009 and 2014. More than 170 articles have been initially identified with those satisfying the classification criteria presented herein. The classification criteria varied significantly spanning across 8 different categories (Figure 4): 1) general BIM theory, 2) applications in Architecture, Engineering and Construction (AEC) field, 3) Integrated analysis, algorithmic processes, computation and optimisation, 4) Life cycle analysis, 5) Sustainability and energy methods, 6) Constructability, project co-ordination and delivery, 7) Structural design and engineering, 8) Cost and economic development. In the selected period of the study (2009-2014), small variations between the individual categories have been observed on the number of published studies. Nevertheless, the general trend shows a yearly increase in the total BIM related articles by more than $20 \%$ on average. This is a good indication of the changes that are currently taking place within the processes of the building industry towards BIM-based applications. Amongst the most prevalent journals on this field are Automation in Construction, Advanced Engineering Informatics, Computing in Civil and Building Engineering, Energy and Buildings, and Journal of Construction and Engineering Management.

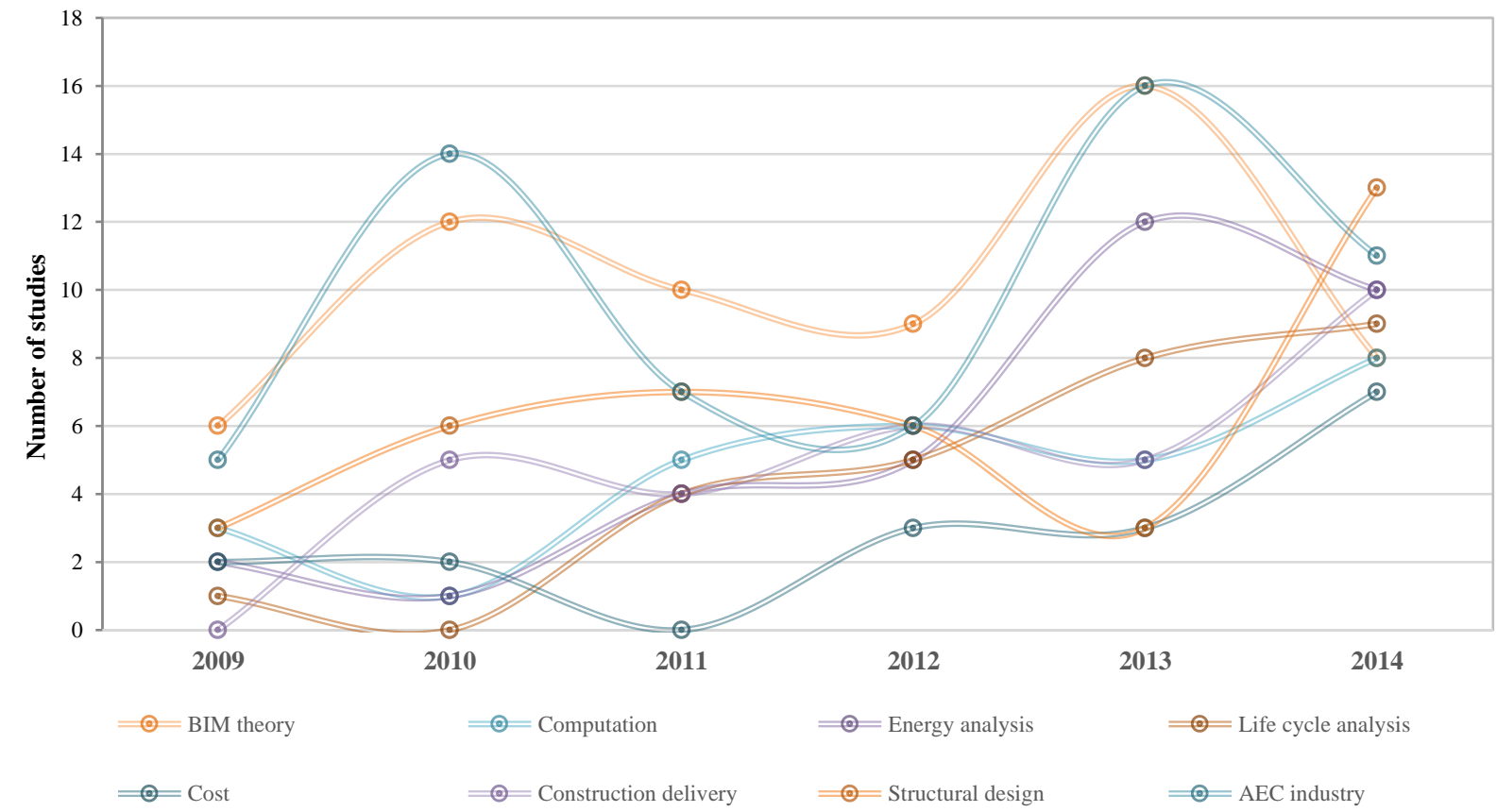

Figure 4 Distribution of BIM related articles per field of study

\section{Sustainable Energy Domain}

Even though BIM technologies are not new, the building industry only recently has begun to acknowledge their capabilities in practical applications related to design and construction. The combination of BIM applications and sustainable design strategies has the potential to produce high-performance energy-efficient design alternatives. Several studies have investigated the development of BIM-based design techniques in order to address a range of sustainability-related issues and enable efficient implementation of LCA modelling. The contribution of BIM in the sustainability assessments of building systems focuses on two explicit perspectives: 1) Integrated project delivery and 2) Design Optimisation (Particularly on energy analysis). For the purposes of this research, we have extended the concept of BIM-based sustainable energy applications to also include life cycle and sustainability ranking methods. BIM and their applications in sustainability rating certification (LEED, BREEAM, BEAM Plus from Hong Kong, Green Mark from Singapore, Green Star from Australia, etc.) have begun to attract the attention of researchers as sustainable strategies can compared whilst the relevant credits can be directly calculated and documented within BIM platforms. In the BIM-based energy models, early applications involved data exports from BIM to external software (IES, EnergyPlus), whereas recent developments have focused on more integrated applications ("plug-ins") where energy calculations can be performed within BIM (Green Building Studio). BIM integrated LCA models especially during the early design stages is an emerging trend. The benefits of BIM within the current LCA applications can be summarised in four main directions: 1) Avoid of manual data re-entry, 2) Allow real-time assessment, 3) Enhance whole-building appraisals, and 4) Implement user-friendly analysis interfaces. In total, 34 articles on the topics of life cycle analysis, energy analysis and sustainable certification analysis have been reviewed (Table 2).

Table 2 Sustainability and energy efficient methodologies in BIM 


\begin{tabular}{|c|c|c|c|}
\hline & Description & References & Key findings \\
\hline $\begin{array}{l}\text { Life cycle } \\
\text { Analysis }\end{array}$ & $\begin{array}{l}\text { Both LCA and Life Cycle } \\
\text { Cost (LCC) systems are } \\
\text { connected with BIM utilising } \\
\text { automated material take-offs } \\
\text { and construction schedules }\end{array}$ & $\begin{array}{l}{[78,79,80,81,82,83,17,70]} \\
{[64,18,30,84,65,10]}\end{array}$ & $\begin{array}{l}\text { Numerous practical BIM-based LCA } \\
\text { applications have been recognised. The majority } \\
\text { of the reviewed studies have included } \\
\text { information about the structural systems when } \\
\text { conducting the LCA calculations }\end{array}$ \\
\hline $\begin{array}{l}\text { Energy } \\
\text { Analysis }\end{array}$ & $\begin{array}{l}\text { Energy performance } \\
\text { methodologies during the } \\
\text { operational phase are } \\
\text { integrated with BIM } \\
\text { applications }\end{array}$ & $\begin{array}{l}{[85,86,87,88,89,90,91,92,93]} \\
{[94,95,96,97,98,99,100,83]}\end{array}$ & $\begin{array}{l}\text { Several conceptual frameworks and case studies } \\
\text { have been explored. The impacts of different } \\
\text { structural systems are rarely accounted when the } \\
\text { purpose of the study is solely the operational } \\
\text { energy performance. }\end{array}$ \\
\hline $\begin{array}{l}\text { Sustainable } \\
\text { Rating } \\
\text { Systems }\end{array}$ & $\begin{array}{l}\text { Green building certification } \\
\text { methodologies such as } \\
\text { BREEAM and LEED are } \\
\text { associated with BIM models }\end{array}$ & {$[101,86,102,103,96,104,18]$} & $\begin{array}{l}\text { Both theoretical frameworks and practical } \\
\text { applications have been reviewed. In the practical } \\
\text { applications material characteristics are enclosed } \\
\text { as part of the relevant credits }\end{array}$ \\
\hline
\end{tabular}

\subsection{BIM-based life cycle energy applications}

This study particularly focuses on the integration of BIM with life cycle energy and other sustainable modules in building structures that have received attention recently. All three stages associated with a building's life cycle have been implemented in order organise and analyse the data from the BIM-based LCA applications in buildings. The embodied phase covers the processes of raw material extraction, manufacturing and construction. The operational phase addresses the energy during the use and maintenance stages. Finally, the end-of-life phase covers the demolition, recycling and reuse stages. Eleven practical applications of BIM-based LCA were identified in the literature (Table 3). Early applications in BIM-based LCA focus mainly on ways that integration of the constituent components can be achieved and less on the decision-making functionalities. The integration comprises of the BIM models, energy analysis models and inventories. In terms of the level of integration, BIM is either used to extract building data (material quantities) which thereafter being processed in external LCA and energy software or all the components of the system are combined within a BIM environment utilising custom user-interfaces. An interesting finding for future applications is that in more than $70 \%$ of the reviewed studies the structural systems of the buildings were included in the LCA assessment. In regards to the BIM software, the most popular one is Autodesk Revit ( $73 \%$ of the cases) followed by other software such as Vico, DProfiler and Blender. Moreover, modelling of the energy performance during the operational phase of the building is critical and it has been applied in almost $65 \%$ of the studies. BIMintegrated energy models (GBS) have been utilised in almost $40 \%$ of these cases. Overall, big inconsistencies are observed in both the LCA and the energy modules with various software been implemented. Finally, from the reviewed cases it becomes evident that whole-life analysis is still not fully operational within BIM and further work is needed in order to achieve complete integration of all the relevant stages. The end-of-life phase has been generally overlooked as whole life analysis was reported in only one study [65].

Table 3 BIM-based LCA methods and key findings $\left({ }^{1} \mathrm{~A}\right.$ : Raw materials and manufacturing, B: Construction, C: Use, D: Maintenance, E: Demolition)

\begin{tabular}{|c|c|c|c|c|c|c|c|c|c|}
\hline \multirow{3}{*}{ Study } & \multirow{3}{*}{$\begin{array}{l}\text { Structural } \\
\text { System }\end{array}$} & \multirow{3}{*}{ BIM Model } & \multirow{3}{*}{$\begin{array}{c}\text { LCA software } \\
\text { \& LCI }\end{array}$} & \multirow{3}{*}{$\begin{array}{c}\text { Energy } \\
\text { Model } \\
\text { (Service life) }\end{array}$} & \multicolumn{5}{|c|}{ Life Cycle Stage $^{1}$} \\
\hline & & & & & \multicolumn{2}{|c|}{$\begin{array}{c}\text { Embodied } \\
\text { Phase }\end{array}$} & \multicolumn{2}{|c|}{$\begin{array}{c}\text { Operational } \\
\text { Phase }\end{array}$} & \multirow{2}{*}{$\begin{array}{c}\begin{array}{c}\text { End of } \\
\text { Life Phase }\end{array} \\
\text { E }\end{array}$} \\
\hline & & & & & $\mathbf{A}$ & B & C & D & \\
\hline $\begin{array}{l}\text { 1. Kulahcioglu } \\
\text { et al. [78] }\end{array}$ & $\bullet$ & $\begin{array}{l}\text { Blender (Open } \\
\text { source) }\end{array}$ & $\begin{array}{l}\text { GaBi using } \\
\text { Ecoinvent }\end{array}$ & N/A & $x$ & $x$ & - & - & - \\
\hline $\begin{array}{l}\text { 2. Mao et al. } \\
{[79]}\end{array}$ & $\bullet$ & Autodesk Revit & $\begin{array}{l}\text { Custom tool using } \\
\text { International and } \\
\text { Chinese test } \\
\text { organisations }\end{array}$ & - & $x$ & $x$ & - & - & - \\
\hline $\begin{array}{l}\text { 3. Wang et al. } \\
{[80]}\end{array}$ & - & Autodesk Revit & $\begin{array}{l}\text { Custom tool using } \\
\text { BEDEC database }\end{array}$ & $\begin{array}{l}\text { Ecotect } \\
\text { (50 year) }\end{array}$ & $x$ & $x$ & $x$ & - & - \\
\hline $\begin{array}{l}\text { 4. Inyim \& Zhu } \\
\text { [81] }\end{array}$ & $\bullet$ & Autodesk Revit & $\begin{array}{l}\text { ATHENA Impact } \\
\text { Estimator }\end{array}$ & $\begin{array}{c}\text { EnergyPlus } \\
\text { (N/A) }\end{array}$ & - & - & $x$ & - & - \\
\hline $\begin{array}{l}\text { 5. Alwan \& } \\
\text { Jones [10] }\end{array}$ & $\bullet$ & N/A & $\begin{array}{l}\text { Custom tool using } \\
\text { Inventory of Carbon } \\
\text { and Energy (ICE) }\end{array}$ & $\begin{array}{c}\text { CIBSE } \\
\text { benchmarks } \\
\text { (10 years) }\end{array}$ & $x$ & $x$ & $x$ & - & - \\
\hline
\end{tabular}




\begin{tabular}{|c|c|c|c|c|c|c|c|c|c|}
\hline $\begin{array}{l}\text { 6. Basbagill et } \\
\text { al. [82] }\end{array}$ & • & DProfiler & $\begin{array}{l}\text { SimaPro, ATHENA } \\
\text { Impact Estimator }\end{array}$ & $\begin{array}{l}\text { eQuest } \\
\text { (N/A) }\end{array}$ & $\times$ & - & $\times$ & $x$ & - \\
\hline $\begin{array}{l}\text { 7. Dawood et al. } \\
\text { [83] }\end{array}$ & N/A & Autodesk Revit & SimaPro & $\begin{array}{c}\text { IES } \\
\text { (N/A) }\end{array}$ & N/A & N/A & N/A & N/A & N/A \\
\hline $\begin{array}{l}\text { 8. Iddon \& Firth } \\
{[64]}\end{array}$ & $\bullet$ & Vico & $\begin{array}{l}\text { Custom tool using } \\
\text { Inventory of Carbon } \\
\text { and Energy (ICE) }\end{array}$ & $\begin{array}{c}\text { Standard } \\
\text { Assessment } \\
\text { Procedure - } \\
\text { SAP (60 } \\
\text { years) }\end{array}$ & $x$ & $\times$ & $x$ & $\times$ & - \\
\hline $\begin{array}{l}\text { 9. Jrade \& } \\
\text { Jalaei }[18]\end{array}$ & $\bullet$ & Autodesk Revit & $\begin{array}{l}\text { ATHENA Impact } \\
\text { Estimator }\end{array}$ & - & N/A & N/A & N/A & N/A & N/A \\
\hline $\begin{array}{l}\text { 10. Stadel et al. } \\
{[84]}\end{array}$ & N/A & Autodesk Revit & SimaPro & $\begin{array}{c}\text { IES and } \\
\text { Green } \\
\text { Building } \\
\text { Studio - GBS } \\
\text { (N/A) }\end{array}$ & $\times$ & $\times$ & $x$ & - & - \\
\hline $\begin{array}{l}\text { 11. Ajayi et al. } \\
{[65]}\end{array}$ & $\bullet$ & Autodesk Revit & $\begin{array}{l}\text { ATHENA Impact } \\
\text { Estimator }\end{array}$ & $\begin{array}{c}\text { Green } \\
\text { Building } \\
\text { Studio - GBS } \\
\text { (30 years) }\end{array}$ & $x$ & $x$ & $\times$ & $x$ & $x$ \\
\hline
\end{tabular}

\subsection{Embodied phase}

Recent developments of BIM integration in the embodied energy phase focus on both material and construction levels. Careful selection of low energy and sustainable materials could significantly reduce the $\mathrm{CO}_{2}$ emissions of the construction phase [105]. BIM-based LCA models have the potential to augment not only demanding management procedures during the construction of building projects but they could also facilitate energy efficient measures during the construction phase [17]. During the construction stage the main categories of emissions are related to the: 1) Construction materials and waste, 2) Fuel consumption from the construction equipment (Diesel, Gasoline, LPG, and Natural gas), 3) Electricity consumption from the construction machinery [106]. BIM applications have been used for benchmarking, monitoring and visualisation of construction operations including materials' specifications, manufacturing embodied carbon and distance to site [107]. This approach significantly helps suppliers and contractors to improve their traditional processes and to better coordinate the progress of construction works (delivery, costs, and carbon). In addition, drawings' information and construction activities' schedules can be integrated within 4D BIM applications to generate emissions' curves during the construction stage from equipment use. Similar computational models could also be used to juxtapose the energy efficiency of different construction methods and optimise their overall sustainability performance $[106,70]$. The integration of BIM with LCA has the potential to automate the process of material specification, whilst quantity take-offs can be done directly in BIM models [17]. This results to better overall data management and helps the design team save time when conducting an LCA [67]. However, further work and quality control is needed in the quantities' measurements in BIM to accurately extract disaggregated building elements' and materials' volumes into the LCA model [84]. Currently research is focusing on advanced ways to semantically associate materials' environmental information (e.g. Environmental Product Declarations - EPD) within BIM material families in order to enhance automation of the LCA pipeline [108].

\subsection{Operational phase}

Previous literature indicates that the energy use of buildings covers a great proportion of the operational phase emissions compared to the embodied phase (i.e. $85 \%$ against 15\%) but in high performing low-energy buildings the embodied emissions could reach up to $45 \%$ over the building lifespan [109]. BIM architecture offers a common user interface for multi-domain energy simulations [97]. From a structural point of view, the impacts of structural systems' thermal mass and thermal properties are the main factors affecting the energy performance during the operational phase $[54,55]$. A building's thermal mass could be a cost-effective method that helps control a building's temperatures and its overall heating and cooling loads and emissions [110]. Although the effective use of thermal mass could have thermal benefits during the use phase of a building, the embodied $\mathrm{CO}_{2}\left(\mathrm{ECO}_{2}\right)$ also need to be factored in when performing an LCA [111]. Therefore, the optimum specification of thermal mass for a particular building can be an extremely complex task involving the evaluation of parameters such as: the duration, the magnitude of excess heating loads and the occupation patterns of the building [112]. The services strategy (mechanical ventilation or natural ventilation) can also influence the effectiveness of thermal mass on the energy savings [113]. Detailed analysis is necessary in order to determine an optimum amount of thermal mass that maximises the returns considering both the cost of thermal mass and the cost savings from the energy reduction. It is important to evaluate the trade-offs of all the life-cycle aspects when selecting building materials and especially when designing energy efficient buildings where the relative importance of the other life-cycle phases and the choice of material are greater [114]. 


\subsection{End-of-life phase}

Even though significant efforts have been put into the sustainable design and construction utilising BIM capabilities, the end-of-life phase has received less attention [115]. However, the information and the data stored within BIM could be utilised to offer systematic assessments of building deconstruction strategies at the end of a building's life [115]. BIM-based deconstruction applications could evaluate recycling, re-use and landfilling potential of primary and secondary structural components and suggest optimised strategies that balance the environmental and economic impacts. Particularly in steel buildings the combination of novel technologies such as BIM, Radio Frequency Identification (RFID) and stress sensors could offer a new paradigm for end-of-life assessments [116]. Building components could be tracked and mapped in BIM's virtual environment, and ultimately re-used for new building applications via Internet auctions at the beginning of a new design. This approach could offer the potential for energy savings and reductions in greenhouse gas emissions and resource use compared to traditional recycling and associated procedures, which tend to be energy intensive.

When adopting non-conventional deconstruction strategies (reuse, recycling, design for disassembly), a number of changes in the design and fabrication of building projects are necessary. The planning of the appropriate deconstruction strategy should start early in the design process and should be considered over the whole life cycle of the building. BIM has the potential to play a major role in this process as modelling of different deconstruction procedures could be computed and help decision-makers make an informed decision that address both economic and energy. For structural engineers this impacts the way:

- The connections between the different structural elements (beam-column or slab-slab) are identified to allow for their deconstruction and reuse,

- Dimensions of building components are rationalised so they can be reused in future applications,

- $\quad$ Materials are specified to last longer (High specification materials)

\section{Engineering Practices Domain}

The construction and engineering industries are slowly shifting towards BIM-based design and delivery processes, whilst the current policies have begun to reinforce this position. The UK government promotes the idea of integrated BIM models and states that until 2016, all government procurement will require all the supply chain members to work in lines of fully collaborative 3D BIM framework [117]. Integrating BIM in engineering practices has also begun to attract attention within the academic community. An extensive review of the current development and future trends of BIM-enabled structural engineering by Chi et al. [118] addresses five areas of research that are expected to become relevant in the future:

1) Extension of structural design's parametric capabilities including functionality, sustainability and safety amongst others to enrich the properties of the BIM applications,

2) Adoption of structural optimisation at early stage in order to maximise the flexibility of the different design solutions and to allow for a higher level integration,

3) Development of easily accessible decision-making tools that incorporate results from the optimisation modules with the effective visualisation technologies,

4) Expansion of high performance numerical methods that apply to large-scale engineering problems, and

5) Enhancing data interoperability with robust and standardised protocols that further improve the quality of collaboration between the various stakeholders.

Furthermore, the effective integration of structural engineering and construction processes requires a cohesive knowledge-based approach that incorporates design and programming details at different project levels (including construction level). Obtaining high level of standardisation BIM integration in structural analysis is a significant challenge and has the potential to effectively streamline structural information exchange. In order to investigate the capabilities of BIM in the structural engineering domain various topics have been recognised in the literature research, which include code compliance, cost estimation, structural safety and construction sequencing, decision-making and visualisation, data integration and optimisation methods. The subsequent sections summarise the main findings on the engineering-related domain fields.

\subsection{Cost Estimation}

Achieving cost reductions is one of the main design objectives of structural engineers in practice. BIM can help structural engineers achieve the required cost reduction during design and construction. There are two main streams of cost estimation within BIM: 1) Export data from BIM and analyse them in a cost-estimating software, 2) Link the cost estimating tool directly with BIM and perform the calculations [119, 120]. BIM models are rich in information and they can be used to automate complex tasks in the building industry such as cost calculations [13]. One of the most useful tasks that can be automated with BIM is quantity takeoff (QTO) [121]. Information entities within BIM such as product, information, quantity information, resource information, price information, schedule information and cost information can help decision-makers to accurately estimate construction costs [122]. In building structures, Otii et al. [123] have proposed a prototype system that utilises BIM representations and allows structural engineers to assess life-cycle cost as well as the combination of carbon and ecological footprint of their designs. The framework integrates the capabilities of Autodesk Revit API with C\# object-oriented language in order to access large datasets of cost and life cycle inventories, whilst testing the conceptual design of a steel-framed building. Feature-based cost estimation modules of steel buildings can be integrated within a common BIM software application [124]: the 
manufacturing process of the steel frame assembly is divided into single processes that include blasting, cutting, beamwelding, sawing, drilling, coping, fabrication of assembly parts, assembling - welding and bolting, post-treatment and painting. Each process is executed at separate cost centres. The comprehensive cost components include raw material, labour, investment cost of equipment and real estate, maintenance and service cost of equipment and real estate, and cost of consumables. In addition, multi-stage BIM-based production cost optimisation can significantly reduce the costs of steel structures [125]. Life cycle costs analysis is considered to be a powerful decision-making tool when assessing different building systems [99]. Furthermore, multidisciplinary design analysis systems in BIM could be integrated with visual graphic interfaces, enabling decision-makers to assess trade-offs between conflicting design variables and get a better understanding of the multi-dimensional design space (e.g. structural costs against overall building life cycle costs - Figure 5) [126]. One limitation of the current BIM-based cost estimations is the need for intervention of a cost estimator (quantity surveyor) at the final stage of the estimation, which involves a certain level of subjectivity. Current research [127] suggests fully automated BIM-based cost estimation with ontological inference and semantic reasoning rules using knowledge of experienced engineers.

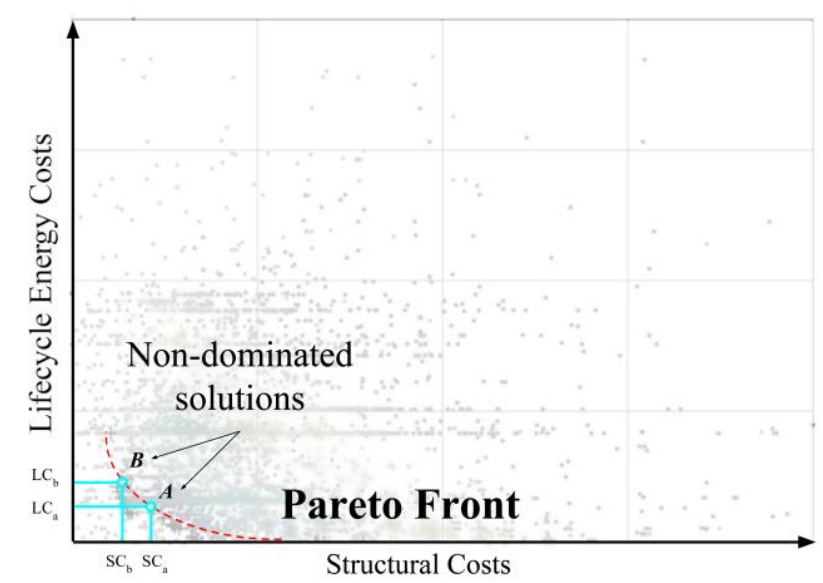

Figure 5 Trade-off between minimum structural capital cost and minimum life cycle energy costs, adapted from [126]

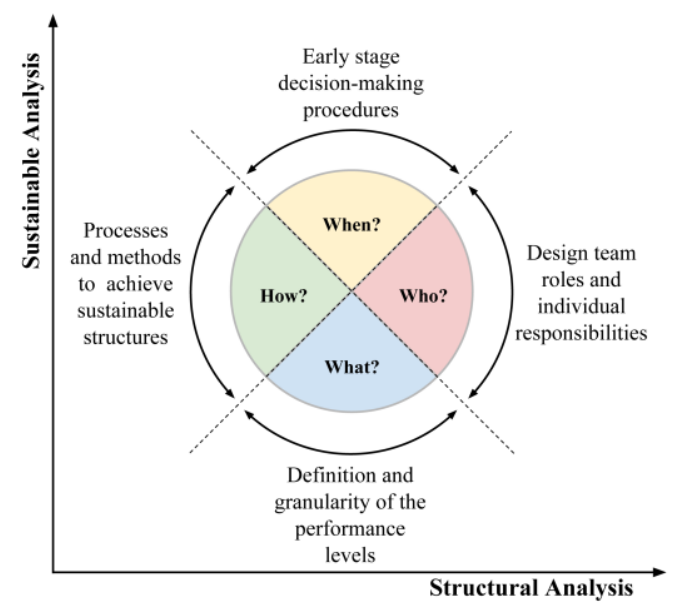

Figure 6 Mapping of sustainable domain against structural domain

\subsection{Safety and Code Compliance}

Safety management during the construction phase of a building project can be improved using BIM applications. Safety related risks of different structural activities could be mapped using the data within the construction plan. In addition, the level of each risk could be ranked based on the probability of occurrence and the severity of consequences in order to provide real-time visual indications to site workers [106]. BIM could reduce the gap between design specification and construction via quality management checks. The overall quality (geometric variables, mechanical properties, materials' selection, on-site calibration, etc.) of the structural products/elements could be effectively managed as individual building components could be inspected against national and industrial codes and guidelines [106]. Nawari [128] has examined an automated code compliance-checking framework (AC3) to verify structural design against the code requirements. BIM data becomes available using the ifcXML schema and gets translated into a Feature-based Model (FBM). Part of the ACI 318-05 code is created in an XML file. Schema rules are established using Language-Integrated Query (LINQ) code to examine the minimum concrete cover requirement of a reinforced concrete beam. Luo \& Gong [129] have additionally specified a BIM-based code compliance checking for a deep foundation using an ontology semantic modelling approach that implements the domain concept as well as the relationships and classification between the system's individual components. The limitations of manual checking efficiency and precision in practice have also been addressed. The proposed ruled-based system has resulted in the development of a knowledge library that assists the automatic generation of the checking list, selection of rules and extraction of required information for code compliance. Huston et al. [130] present BIM as a potential framework for data integration, synthesis, retrieval and rapid display that can be used as an intelligent structural health management system. Finally, Hu \& Zhang [131] have adopted the archetypal system, 4D-GCPU 2009 in order to specifically address the structural safety control during construction. They have justified the overall performance of the system by integrating it into the construction management of three case studies - a stadium, a tower and a bridge. In the tested scenarios, the following attributes were identified: 1) improvements in construction efficiency using resource allocation and reduction in construction conflicts, 2) better owner's supervision as well as review and management expansion using schedule and cost conflict analyses, and 3) integration of design and construction safety requirements by implementing time dependent structural analysis.

\subsection{Buildability and construction processes}

Improvements in the construction processes and building scheduling can be enhanced with 4D BIM applications. Liu et al. [132] have applied BIM to bridge projects to improve the efficiency of design and construction. They have proposed a conceptual optimisation module as well as a detailed optimisation module, optimisation of construction 
scheduling and construction management. 3D structural BIM can be also implemented as a new modelling approach for placing reinforcement bars in concrete flat slabs based on a parametric design technology [133]. Song et al. [134] have developed an optimisation system, which manages scheduling of important site based construction processes: the $4 \mathrm{D}$ simulation function with the optimisation process includes data from the 3D model by processing IFC classes and predefined calculation formulas determining the amount of work required for the main construction operations. The information about the work methods, the human resources and the information about the materials and construction machinery are specified by the user. Dynamic 4D BIM-based simulation framework can automatically create and simulate construction schedules the cost calculations associated with the relevant scheduling [135]. Tulke \& Hanff [136] on the other hand, have developed a similar 4D system that utilises geometric data and time schedules within the BIM model to estimate the construction sequence. Lee \& Bae [137] have improved the efficiency analysis of a Set-Based Design (SBD) procedure using Structural Building Information Modelling (S-BIM) in order to obtain solutions that improve constructability, safety and economic effectiveness of buildings. S-BIM is a subset of BIM that is related to structural engineering and it involves structural analysis procedures providing a flexible environment for interoperability on an engineering project. A case study - a 65-storey mix-used tower with 5-storey basements indicates that the proposed design approach achieves higher efficiency levels when compared to the existing SBD with the 2D method due to the enhanced analysis capabilities and increased stakeholder collaboration.

\subsection{Optimisation and decision-making}

The transition from traditional engineering approaches to whole-building "performance-based" and "performancedriven" approaches requires good knowledge of optimisation algorithms and integrated software applications such as BIM [138]. Performing real-time optimisation and decision-making within BIM is one of the industry's future challenges [139]. A novel BIM based structural optimisation framework that achieves efficient and environmentally responsible steel design solutions (I-beams) using a custom genetic algorithm solver and an integrated Life Cycle Assessment component was previously proposed by the authors [140]. In the tested prototypical structure we have showed that by maximising the structural efficiency of the steel beams, significant savings of up to $20 \%$ could be achieved compared to the an basic structure with standard catalogue sections [140]. Rafiq \& Rustell [141] have integrated an Interactive and Visual Clustering Genetic Algorithm (IVCGA) into a BIM environment to enhance the design information and allow the solutions to be viewed as building information models. The proposed configuration allows multidisciplinary design criteria to be assessed by architects, structural engineers, and building physicists enabling a wide range of concept designs. A case study has been implemented in order to test the efficiency of the multi-objective optimisation search engine, which has exhibited an adequate behaviour in finding the optimum solutions based on the design team specified requirements such as minimum number of columns and maximum open floor area, minimum structural frame cost, maximum lighting and natural ventilation. In addition, Porwal \& Hewage [142] have established a BIM-based rebar optimisation analysis that minimises the trim loss of rebar using a Simulated Annealing Heuristic algorithm. The proposed approach was validated in a two-storey reinforced concrete structure, in which the cutting losses of the bars were substantially reduced. They also have found that more cost-effective results could be obtained when higher-diameter rebar are used. Faghini et al. [143] have additionally demonstrated an augmented approach that automatically develops and generates construction sequencing using a genetic algorithm and BIM. The geometric information is derived from the 3D model and it is inherited from the genetic algorithm module. The fitness function of the application is linked to the constructability score, which is calculated based on the constraints and rules defined by the Matrix of Constructability Constraints (MoCC). The results from the novel methodology show that $100 \%$ constructible schedules can be created from randomly generated schedules. Multiperformance sustainable optimisation frameworks have also begun to attract the attention of researchers. The amalgamation of quantitative computational models with decision-makers' preferences under a common BIM platform has the potential to augment the energy and environmental performance of building structures, whilst they can increase the adoption levels of sustainable structural alternatives by the stakeholders in the industry [144].

\section{Problem Formulation}

The research demonstrates that the developments of BIM applications in structural engineering and sustainable energy domains are very fragmented and disaggregated. Despite the fact that a significant volume of BIM-related research has focused on this topic following different research routes, the combination of concepts and definitions between the two domains often remain inaccessible or poorly integrated. Whilst the underlying reasons of this state are profound as the internal processes in each field are driven by different objectives, it is sensible to explore theoretical analogies and practical parallelisms between the two domains at a deeper level by interpreting the capabilities of BIM. In order to obtain a higher degree of aggregation between these concepts and in order to establish new decision paradigms in the industry, consolidated frameworks that map the structural domain with the energy efficient domain would need to address four interconnected fields of practice (Figure 6): There is a need for early stage decision-making procedures to address the life cycle energy and sustainability performance of building structures in real-time. Currently the majority of life cycle assessments are being used for ranking purposes retrospectively, whilst they rarely address the entire life of a building due to the lack of continuous data. Additionally, the relationships between the embodied and the operational energy phases are not clearly specified. Robust early decision procedures could mitigate associated risks, whilst energy and sustainability strategies could become more effective as projects move forward. BIM-based knowledge systems that include data, information and experiences from previous projects could also be utilised as 
design guidelines in new projects. The adoption of energy efficient decision procedures that generate structural efficient solutions both in terms of engineering performance and long-term environmental impacts need to be enhanced in structural engineers' common practice. However, the nature of the profession currently focuses on strictly engineering attributes and less on sustainability objectives. As a result structural changes are also necessary at organisation level in order to facilitate a bigger change in the industry. The educational variable can play a significant role in shaping a new, more sustainable and energy efficient decision paradigm in building structural engineering. College programmes that introduce LCA and BIM at both undergraduate and postgraduate levels could help young graduates to get a deeper understanding of the energy challenges they will have to face once they enter the profession. Furthermore, the complexity of building design lies on the effective collaboration of various stakeholders, of both technical and non-technical nature. BIM could play a significant role in this field as it can enhance the communication between the structural engineers and the rest of the design team, whilst it could improve remote design optioneering through rich visualisation procedures. The definition of the performance requirements needs to be clearly recognised. Currently, there are no policy requirements to associate sustainable energy performance with structural engineering practice. Therefore, integrated policy measures that address the subsequent life cycle energy objectives not only at a building level but also at a structural system level would further reinforce this field. A systematic approach to building design considers buildings as complex systems that incorporate a variety of sub-systems with their individual modules such as architectural model, structural model, energy model, cost model, mechanical system model, indoor air quality model, etc. BIM integrated analysis and delivery models can identify performance relationships between different building systems. The current nature of the comparative LCA models in building structures are not sufficiently integrated in practical structural engineering decision-making processes. Therefore, low energy and sustainable approaches such as LCA connected with engineering optimisation modules could be used by structural engineers not only as an assessment procedure at the end of a project but as an effective optioneering method of different design alternatives. Research has shown that the purpose of the LCA is not limited to comparisons between different material families. Combined with cost estimating and construction scheduling techniques it could offer novel decision paradigms in structural engineering.

\section{Towards consolidated decision frameworks for structural and sustainability domains}

As illustrated in the preceding literature review, the existing decision-making procedures in the engineering and sustainable domains require multilevel hierarchies in order to combine notions from both concepts. The selection of the appropriate structural typology or material system is often imposed by factors other than the direct environmental and energy performance. Common driving factors are economic, construction programme, market needs, contractor requirements and client preferences. In this section, the foundation of a multilevel optimisation framework that stimulates the delivery of sustainable building structural systems is established. In addition, the integration of collective and individual intelligence across the different groups of stakeholders involved in the decision rationale in a single BIM platform is examined. The proposed multilevel decision model (Figure 7) aims to assist structural engineers and other decision-makers to evaluate design alternatives during the early decision stages (conceptual and detailed) in a holistic manner. The proposed decision model takes into consideration the impacts of life cycle sustainability and energy efficiency measures as well as embedded knowledge at both individual and organisation levels. Phase I includes the development of the structure's generic optimised form that outlines the design briefs' sustainable energy requirements, whilst it establishes the explicit engineering characteristics. The second concept is related to advanced and technical design processes at Phase II, where the structural analysis models involve significant time commitment and computational effort to determine the structural systems' explicit attributes. The corresponding filtering assemblies (Figure 8) entail the set of specifications and rules for the transparent and systemic characterisation of each field at both phases of the decision process. Looking at the general formulation of Characterisation at Level 1 the preliminary interactions between the various stakeholders and experts (technical and non-technical) enable the recognition of the design boundaries, whilst they help define the project's brief overview (Level 1.1). The results obtained from the processes at Level 1.1 lead to the creation of the generic design objectives' matrix within Level 1.2 comprising of both quantitative and qualitative sustainability criteria (life cycle energy measures) that could be applied at building and system levels. The development of the conceptual BIM model that summarises the early capabilities in information exchange, communication and collaboration policies and technology strategies is captured at Level 1.3. Furthermore, the Development at Level 2 comprises of the processes associated with the problem development and the articulation of alternative options. Level 2.1 begins with the translation of the sustainable design requirements that have been recognised at Level 1 into engineering criteria and constraints enabling the easier implementation of computational models and simulation algorithms at Level 2.2. The main benefit of the aforementioned steps is that they facilitate the development of a quantitative model for the entire decision procedure at Level 2.3. At Level 3 Appraisal, stakeholders' interactions that are related to the negotiation and the final decision-making are presented. Level 3.1 includes the consolidation of design alternatives based on the specific project's requirements, whilst the assessment of the different alternatives based on the stakeholders' expert knowledge and opinion occurs at Level 3.2. The assessment at Level 3.2 is based not only on quantitative appraisals but also on qualitative data reviews. The inclusion of local knowledge at this stage is a crucial step in understanding the primary density of the entire decision process and needs to be thoroughly addressed. Finally, the decision-making procedures end with the selection of a single solution that achieves the highest consensus amongst the various decision-makers, whilst it satisfies the initial engineering and energy performance criteria. 


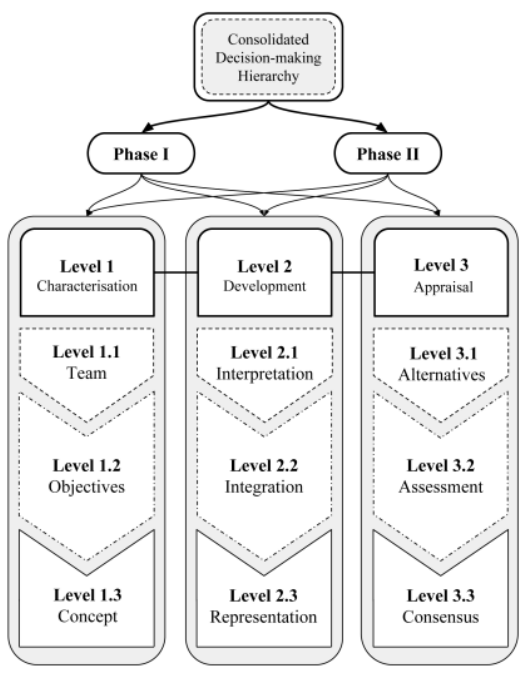

Figure 7 Multi-level decision hierarchy

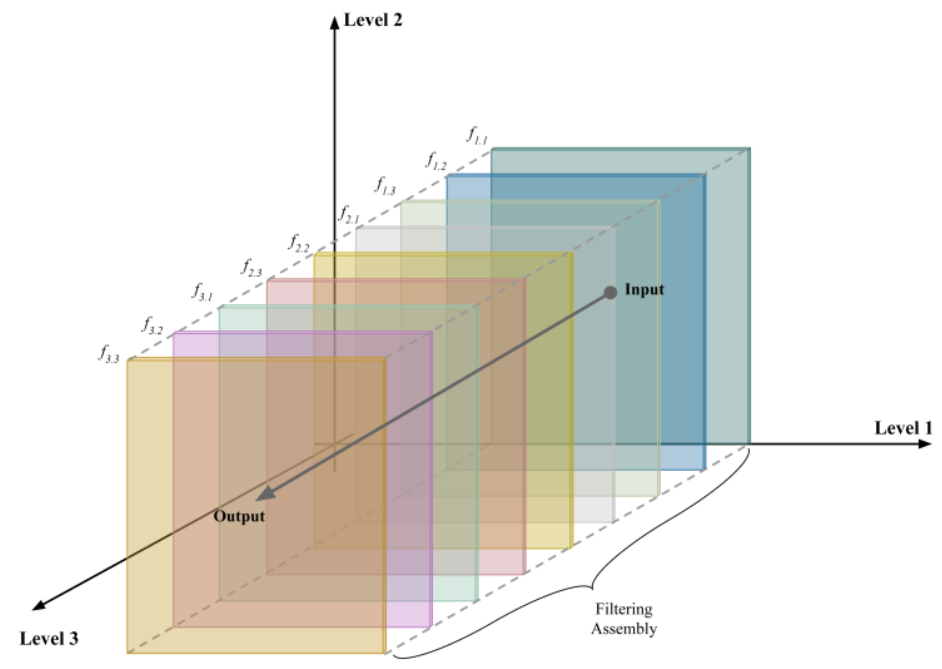

Figure 8 Conceptual filtering representation

\section{Discussion}

The main notion behind the current study is that structural systems cannot be examined in isolation when addressing sustainable energy concepts but as a rather integrated building component that interacts with the rest of the building sub-systems (architectural, construction, mechanical, energy). Therefore, by conceptualising the main principles and complexities that drive the decisions in the building industry stakeholders would be able to identify building systems that satisfy the overall sustainability, energy and engineering performance objectives. Traditionally sustainable structural analysis focuses on the constituent components or materials performance by optimising the individual structural elements, which may result in making the overall building system less efficient simply by not addressing the interrelationships with other energy systems (e.g. interactions of embodied with operational energy). Additionally, bounce on effects of structural changes on other building systems are rarely considered. Hence, holistic engineering approaches that maximise the mechanical, economic, environmental and energy performance of a building during its whole life cycle are still underdeveloped. BIM-integrated systematic procedures for analysis and decision-making need to be established focusing on how the system's individual material elements interact with the structural components to generate low energy and sustainable buildings. For example, when structural engineers are optimising the thickness of floor system they need to perform an LCA not only at system but also at building level. If the optimum solution increases the depth of the floor in order to minimise the embodied energy of the system the overall performance at building level might not be optimum due to the increased wall area (taller building). Therefore, the macroscopic mechanisms of the interconnected systems must be studied in order to understand the entire system's underlying principles.

At the sustainability domain, BIM utilises geometric data and time schedules in simulation frameworks to perform daylighting, energy and structural analyses along with cost calculations, whilst it can be used to monitor and assess environmental impacts and energy use during the operational phase of a building. Various dynamic components during the operational phase are hard to be quantified such as the occupant behaviour. In addition, there are several parameters that complicate the implementation of life cycle based decision-making, as there is a limited standardisation in the individual building components and sub-systems that often restrict the acquisition of accurate data inventories. The precise definition of functional units or system boundaries can also become problematic due to the complexity of all the individual processes and the associated stakeholders involved. Furthermore, it is challenging to quantify the exact replacement rates of building components from cradle-to-grave, whilst the estimation of the corresponding costcarbon ratios of future design alterations or policy alterations become tenuous. In the application of the existing sustainable energy analysis techniques within BIM further developments are required towards:

- Robust ontology based life-cycle energy inventories that provide consistent material data inventory of the construction supply chain could deliver enriched and consistent assessment procedures that minimise the method's results variability,

- New design models that integrate cost effective energy measures including several future uncertainty parameters such as climate change and economic metrics, whilst thoroughly addressing the relationships between embodied and operation environmental energy impacts in buildings,

- Flexible protocols for the specification of maintenance/end-of-life design parameters could mitigate the uncertainties that occur from future changes in the building's spatial arrangements combined with possible changes-of-use in terms of occupancy or/and ownership.

The current practice has showed that BIM integrated structural engineering domain focus on the project management and efficient delivery of the building components via the enhanced information flow between the design team 
members and the detailed construction organisation. BIM has been used as an efficient project delivery system that enhances the team's capabilities to design a building, to monitor and to manage the processes during the maintenance phases and simulate the relevant end-of-life deconstruction sequencing. However, in order to achieve energy efficient and sustainable building structures a higher degree of BIM integration between the different engineering systems and the numerous building levels is also necessary. The authors recognise three main approaches that could augment the existing structural engineering/energy efficient domains:

- Embodied Phase: Advancing the current optimisation methods and decision-making tools in order to provide recommendations for actions that improve building sustainability performance whilst they enable the design team to assess the effectiveness of those measures in real time,

- Operational Phase: Combining it with building management systems and advanced visualisation solutions, which could enable the design team to optimise carbon emissions by evaluating activities related to cost, carbon, energy efficiency, consumption reporting and mitigation measures,

- $\quad$ End-of-Life: Merging design analytics and monitoring/predictive processes could be incorporated in the existing facility management systems to identify failures of building components, effectively maintain them and ultimately extend the life cycle of the building.

\section{Conclusion}

Only recently and under the global environmental pressures within the built environment structural engineers have begun to consider the sustainability impacts of their proposals seeking for energy efficient analysis methodologies and decision-making tools that could offset the environmental burdens of their design solutions. This radically changes the design criteria in building structures, as the underlying complexity of quantifying the environmental energy performance of such structures is not an easy task especially when taking into account the long-term implications at building level (discrepancies of embodied energy and operational energy phases). The reluctance, the conservatism and the fragmentation of the construction industry sector have also slowed down the integration and adoption of novel analytical models, which have resulted in further skepticism in the development of holistic engineering decisionmaking processes. The study has presented the recent developments in BIM-based design processes that explore the developments in both the structural engineering and the life cycle energy performance capabilities. From these processes, evaluation frameworks that quantify the performance criteria of sustainable and energy efficient structural systems using common and novel construction techniques could emerge, whilst intuitive decision workflows in the future engineering practices could also be consolidated. The benefits of such engineering approaches are greater particularly during the early design development of buildings where decisions cost less, are more effective and they are easier to be implemented. The specification of a theoretical consolidated decision model has been presented aiming to bridge the two domains under the capabilities of BIM. Practical applications of the consolidated paradigm are also discussed. The design of future building components in an intelligent and efficient way would require the integration of building and construction automation processes, business systems, information technologies and enhanced knowledge transfer between the various disciplines and organisations in the building industry.

\section{Acknowledgments}

This research has been made possible through funding provided by the Engineering and Physical Sciences Research Council (EPSRC) and from Price \& Myers LLP via the UCL EngD Centre in Virtual Environments, Imaging and Visualisation and this is gratefully acknowledged here.

\section{References}

[1] M. Khasreen, P. Banfill and G. Menzies, "Life-cycle assessment and the environmental impact of buildings: a review," Sustainability, pp. 674-701, 2009

[2] A. Singh, G. Berghorn, S. Joshi and M. Syal, "Review of Life-Cycle Assessment Applications in Building Construction," Journal of Architectural Engineering, vol. 17, pp. 15-23, 2011.

[3] N. Perez, G. Baird and A. Buchanan, "The influence of construction materials on the life cycle energy use and carbon dioxide emission of medium sized commercial buildings," in Proceedings of the World Conference Sustainable Building Conference, Melbourne, Australia, 2008.

[4] A. Puskas, J. Virag, L. Moga, H. Szilagyi, M. Bindea and S. Kollo, "Environmental impact of masonry and RC frame structures," in Advances in Environmental impact of masonry and RC frame structures," in Advances in En
Sciences, Development and Chemistry, Santorini, Greece, 2014.

[5] J. Danatzko and H. Sezen, "Sustainable Structural Design Methodologies," Practice Periodical on Structural Design and Construction , pp. 186-190, November 2011.

[6] J. Anderson and R. Silman, "A Life Cycle Inventory of Structural Engineering Design Strategies for Greenhouse Gas Reduction," Structural Engineering Interntional, vol. 19 , no. 3, pp. 283-288, 2009.

[7] T. Ibn-Mohammed, R. Greenough, S. Taylor, L. Ozawa-Meida and A. Acquaye, "Operational vs. embodied emissions in buildings - A review of current trends," Energy and Buildings 66, pp. 232-245, 2013.

[8] A. Takano, S. Pal, M. Kuittinen, K. Alanne, M. Hughes and S. Winter, "The effect of material selection on life cycle energy balance: A case study on a hypothetical building model in Finland," Building and Environment, vol. 89, pp. 192-202, 2015

[9] D. Miller, J.-H. Doh, K. Panuwatwanich and N. van Oers, "The contribution of structural design to green building rating systems: An industry perspective and comparison of life cycle energy considerations," Sustainable Cities and Society, vol. 16, pp. 39-48, 2015a
[10] Z. Alwan and P. Jones, "The importance of embodied energy in carbon footprint assessment," Structural Survey, vol. 32, no. 1, pp. 49-60, 2014.

[11] B. Succar, "Building information modelling framework: A research and delivery foundation for industry stakeholders," Automation in Construction 18, pp. 357-375, 2009a.

[12] C. S. Dossick, M.ASCE and G. Neff, "Organizational Divisions in BIM-enabled Commercial Construction," Journal of Construction Engineering and Management, pp. $459-467,2010$

[13] F. Cheung, J. Rihan, J. Tah and E. Kurul, "Early stage multi-level cost estimation for schematic BIM models," Automation in Construction, vol. 27, pp. 67-77, 2012.

[14] Y. Arayici, P. Coates, L. Koskela, M. Kagioglou, C. Usher and K. O'Reilly, "Technology adoption in the BIM implementation for lean architectural practice," Automation in Construction, pp. 189-195, 2011.

[15] W. Kymmell, Building Information Modelling: Planning and Managing Construction Preojects with 4D CAD and Simulations, New York: McGraw Hill, 2008.

[16] BSI, "Constructing the Business Case: Building Information modelling," British Standards Institution, London-UK, 2010

[17] S. Russell-Smith and M. Lepech, "Dynamic Life Cycle Assessment of Building Design and Retrofit Processes," Computing in Civil Engineering, pp. 760-767, 2011

[18] A. Jrade and F. Jalaei, "Integrating building information modelling with sustainability to design building projects at the conceptual stage," Building Simulation, vol. 6, pp. 429-444, 2013.

[19] G. Ding, "Sustainable construction-role of environmental assessment tools," Journal of Environmental Management, vol. 86, pp. 451-464, 2008.

[20] K. Kohler and S. Moffatt, "Life cycle analysis of the built environment," UNEP industry and environment, pp. 17-21, 2003.

[21] S. Lu, I. Wu and B. Hsiung, "Applying building information modelling in environmental impact assessment for urban deep excavation projects," Gerontechnology, vol. 11, no. 2, 2009. 
[22] A. O'Reilly, "Using BIM as a tool for cutting construction waste at source," Construction Research and Innovation 3, pp. 28-31, 2012.

[23] P. Rajendran and C. Gomez, "Implementing BIM for Waste Minimisation in the Construction Industry: A Literature Review," in 2nd International Conference on Management, Langkawi Kedah, Malaysia, 2012.

[24] M. N. Zeng, "Future of Green BIM Designing and Tools," Advanced Materials Research 374, pp. 2557-2561, 2012.

[25] M. Rekola, T. Mäkeläinen and T. Häkkinen, "The role of design management in the sustainable building process," Architectural Engineering and Design Management 8, pp. 78-89, 2012.

[26] S. Firoz and S. K. Rao, "Modelling Concept of Sustainable Steel Building by Tekla Software," International Journal of Engineering 1, pp. 18-24, 2012

[27] J. H. Park, J. L. Park, J. H. Kim and J. J. Kim, "Building Information Modelling based Energy Performance Assessment System - An assessment of the Energy
Performance Index in Korea," Construction Innovation: Information, Process, Performance Index in Korea," Const
Management 12, pp. 335-354, 2012.

[28] B. McAuley, A. Hore and R. West, "Use of Building Information Modelling in Responding to Low Carbon Construction Innovations: an Irish Perspective," in Proceedings of the Joint CIB W055, W065, W089, W118, TG76, TG78, TG8 International Conference on Management of Construction: Research to Practice, Montreal, 2012

[29] J. Zuo and Z.-Y. Zhao, "Green building research - current status and future agenda A review," Renewable and Sustainable Energy Reviews, vol. 30, pp. 271-281, 2014

[30] Y. Yuan, J. Yuan and X. Fan, "Integration of BIM and Intelligence Algorithm for BLC Energy Consumption Evaluation and Optimization: Principles and Framework," Journal of Convergence Information Technology (JCIT), vol. 8, no. 20, pp. 502-509, May 2013

[31] G. Weisenberger, "Sustainability and the Structural Engineer," Practice Periodical on Structural Designa and Construction, pp. 146-150, November 2011.

[32] R. Solnosky, "Current Status of BIM Benefits, Challenges, and the Future Potential for the Structural Discipline," Pittsburgh, Pennsylvania, United States, 2013.

[33] N. Nawari, L. Itani and E. Gonzalez, "Understanding Building Structures Using BIM Tools," Miami, Florida, United States, $2011 \mathrm{~b}$

[34] R. Solnosky, "Integrated Structural Practices via Emerging Methods," Boston, Massachusetts, United States, 2014.

[35] D. Miller and J.-H. Doh, "Incorporating sustainable development principles into building design: a review from a structural perspective including case study," The structural Design of Tall and Special Buildings, vol. 24, no. 6, pp. 421-439, 2014

[36] T. Ramesh, R. Prakash and K. Shukla, "Life cycle energy analysis of buildings: an overview," Energy and Buildings 42, pp. 1592-1600, 2010.

[37] S. Russell-Smith, M. Lepech, R. Fruchter and Y. Meyer, "Sustainable target value design: integrating life cycle assessment and target value design to improve building energy and environmental performance," Journal of Cleaner Production, vol. 88, pp. 43-51, 2015.

[38] ISO 14040, "ISO 14040 International Standard in Environmental Management - Life Cycle Assessment - Principles and Framework," International Organisation for Standardization, Geneva, Switzerland, 2006.

[39] G. Finnveden, M. Hauschild, T. Ekvall, J. Guinee, R. Heijungs, S. Hellweg, A. Koehler, D. Pennington and S. Suh, "Recent developments in Life Cycle Assessment," Journal of Environmental Management, pp. 1-21, 2009.

[40] R. Cole and P. Kernan, "Life-cycle energy use in office buildings," Building and Environment 31, pp. 307-317, 1996.

[41] N. Huberman and D. Pearlmutter, "A life-cycle energy analysis of building materials in Negev desert," Energy and Buildings 40, pp. 837-848, 2008.

[42] G. Ding, "The development of multi-criteria approach for the measurement of sustainable performance for built projects and facilities," Sydney, Australia, 2004

[43] T. Chen, J. Burnett and C. Chau, "Analysis of embodied energy use in the residential building of Honk Kong," Journal of Energy 26, pp. 323-340, 2001

[44] G. Treloar, "A comprehensive embodied energy analysis framework, $\mathrm{PhD}$ thesis," Deakin University, Australia, 1998.

[45] J. Yang, P. Brandon, T. Sidwell and A. Sidwell, Smart and Sustainable Buil Environment, Blackwell Publishing, 2005.

[46] B. Reddy and K. Jagadish, "Embodied energy of common and alternative building materials and technologies," Energy and Buildings 35, pp. 129-137, 2003.

[47] O. Ortiz, F. Castells and G. Sonnemann, "Sustainability in the construction industry: A review of recent developments based on LCA," Construction and Building Materials, vol. 23, pp. 28-39, 2009.

[48] A. Dimoudi and C. Tompa, "Energy and environmental indicators related to construction of office buildings," Resources, Conservation and Recycling, vol. 53, pp. 86-95, 2008.

[49] S. Xing, Z. Xu and G. Jun, "Inventory analysis of LCA on steel and concrete construction office buildings," Energy and Buildings 40, pp. 1188-1193, 2008.

[50] L. Gustavsson and R. Sathre, "Variability in energy and carbon dioxide balances of wood and concrete building materials," Building and Environment 41, pp. 940-951,

[51] N. Hossaini, B. Reza, S. Akhtar, R. Sadiq and K. Hewage, "AHP based life cycle sustainability assessment (LCSA) framework: a case study of six storey wood frame and concrete frame buildings in Vancouver," Journal of Environmental Planning and Management, pp. 1-24, 2014.

[52] S. John, B. Nebel, N. Perez and A. Buchanan, "Environmental Impacts of Multistorey Buildings Using Different Construction Materials," Christchurch, New Zealand, 2008

[53] W. Omar, J.-H. Doh, K. Panuwatwanich and D. Miller, "Assessment of the embodied carbon in precast concrete wall panels using a hybrid life cycle assessment approach in Malaysia," Sustainable Cities and Society, vol. 10, pp. 101-111, 2014.
[54] B. Venkatarama Reddy and K. Jagadish, "Embodied energy of common and alternative building materials and technologies," Energy and Buildings 35, pp. 129$137,2003$.

[55] R. Kahhat, J. Crittenden, F. Sharif, E. Fonseca, K. Li, A. Sawhney and P. Zhang, "Environmental Impacts over the Life Cycle of Residential Buildings Using Differe Exterior Wall Systems," Journal of Infrastructure Systems, vol. 15, pp. 211-221,
2009 .

[56] D. Miller, J.-H. Doh and M. Mulvey, "Concrete slab comparison and embodied energy optimisation for alternate design and construction techniques," Construction and Building Materials, vol. 80, pp. 329-338, 2015.

[57] D. Miller, J. Doh, H. Guan, M. Mulvey and S. Fragomeni, "Environmental impact assessment of post tensioned and reinforced concrete slab construction," in assessment of post tensioned and reinforced concrete slab construction," in
Proceedings of the 22nd Australasian Conference on the Mechanics of Structures and Materials - From Materials to Structures: Advancement through Innovation, and Mater $2013 \mathrm{a}$.

[58] D. Miller, J.-H. Doh and T. Peters, "Environmental Impact Assessment of Pos Tensioned and Conventional Reinforced Concrete Slab Design," in ISEC-7, Honolulu, Hawai , 2013

[59] "Integrated environmental design and optimization of concrete floor structures for buildings," in World Sustainable Building Conference, Tokyo, Japan, 2005.

[60] C. Fiala and P. Hajek, "Environmentally based optimization of RC slab floor structures," in CESB , Prague, Czech Republic, 2007.

[61] P. Foraboschi, M. Mercanzin and D. Trabucco, "Sustainable structural design of tall buildings based on embodied energy," Energy and Buildings, vol. 68, pp. 254-269, 2014

[62] S. Tae, C. Baek and S. Shin, "Life cycle CO2 evaluation on reinforced concrete structures with high-strength concrete," Environmental Impact Assessment Review, vol. 31, pp. 253-260, 2011

[63] S. Lee, W. Park and H. Lee, "Life cycle $\mathrm{CO} 2$ assessment method for concrete using $\mathrm{CO} 2$ balance and suggestion to decrease $\mathrm{LCCO} 2$ of concrete in South-Korean apartment," Energy and Buildings, vol. 58, pp. 93-102, 2013.

[64] C. Iddon and S. Firth, "Embodied and operational energy for new-build housing: A case study of construction methods in the UK," Energy and Buildings, vol. 67, pp. $479-488,2013$

[65] S. Ajayi, L. Oyedele, B. Ceranic, M. Gallanagh and K. Kadiri, "Life cycle environmenta performance of material specification: a BIM-enhanced comparative assessment," International Journal of Sustainable Building Technology and Urban Development, 2015.

[66] M. Dixit, J. Fernandez-Solis, S. Lavy and C. Culp, "Identification of parameters fo embodied energy measurement: A literature review," Energy and Buildings, vol. 42 , pp. 1238-1247, 2010

[67] J. Diaz and L. Anton, "Sustainable Construction Approach through Integration of LCA and BIM Tools," Computing in Civil and Building Engineering, pp. 283-290, 2014.

[68] A. Moncaster and J.-Y. Song, "A comparative review of existing data and methodologies for calculating embodied energy and carbon of buildings," International Journal of Sustainable Building Technology and Urban Development, vol. 3, no. 1, pp. 26-36, 2012

[69] S. Lisbeth Hsu, "Life cycle assessment of materials and construction in commercial structures:variability and limitations - Master Thesis," MIT, Cambridge, Massachusetts, 2010

[70] B. Li, Fu, F.F, H. Zhong and H. Luo, "Research on the computational model for carbon emissions in building construction stage based on BIM," Structural Survey, vol. 30, no. 5, pp. 411-425, 2012.

[71] C.-H. Liu, M. Lenzen and J. Murray, "A disaggregated emissions inventory for Taiwan with uses in hybrid input-output life cycle analysis (IO-LCA)," Natural Resources Forum, vol. 36, pp. 123-141, 2012.

[72] G. Treloar, P. Love and O. I.-R. U. Faniran, "A hybrid life cycle assessment method for construction," Construction Management and Economics, vol. 18, pp. 5-9, 2000

[73] S. Miller, S. Moysey, B. Sharp and J. Alfaro, "A Stochastic Approach to Model Dynamic Systems in Life Cycle Assessment," Journal of Industrial Ecology, vol. 17, no. 3, pp. 352-362, 2012.

[74] E. Wang and Z. Shen, "A hybrid Data Quality Indicator and statistical method for improving uncertainty analysis in LCA of complex system e application to the wholebuilding embodied energy analysis," Journal of Cleaner Production, vol. 43, pp. 166$173,2013$.

[75] M. Lenzen and R. Crawford, "The Parth Exchange Method for Hybrid LCA," Environmental Science \& Technology, vol. 43, no. 21, pp. 8251-8256, 2009.

[76] A. Halog and Y. Manik, "Advancing Integrated Systems Modelling Framework for Life Cycle Sustainability Assessment," Sustainability, vol. 3, pp. 469-499, 2011.

[77] B. Bertin, V.-M. Scuturici and J.-M. Pinon, "A Semantic Approach to Life Cycle Assessment Applied on Energy Environmental Impact Data Management," in EDBT '12, Berlin, Germany , 2012.

[78] T. D. J. Kulahcioglu and C. Toklu, "A 3D analyzer for BIM-enabled Life Cycle Assessment of the whole process of construction," HVAC\&R Research, vol. 18, no. 1-2, pp. 283-293, 2012

[79] C. Mao, Q. Shen, J. Wang and C. Lu, "A BIM-enabled Estimating Framework of Embodied Emissions of Building Materials for Optimization in Design Stage: A Case Study," International Journal of Digital Content Technology and its Applications, vol. 7, no. 8, pp. 645-653, 2013 .

[80] E. Wang, Z. Shen and C. Barryman, "A Building LCA Case Study Using Autodesk Ecotect and BIM Model," in 47th ASC Annual International Conference Proceedings, 2011

[81] P. Inyim and Y. Zhu, "A Framework for Integrated Analysis of Building Designs Using Life Cycle Assessment and Energy Simulation," in ICCREM 2013, Karlsruhe, Germany, 2013. 
[82] J. Basbagill, F. Flager, M. Lepech and Fischer, "Application of life-cycle assessment to early stage building design for reduced embodied environmental impacts," Building and Environment, vol. 60, pp. 81-82, 2013.

[83] S. Dawood, R. Lord and N. Dawood, "Development of visual whole Life-cycle energy assessment framework for built environment," in Proceedings of the 2009 Winter Simulation Conference, Austin, Texas, 2009.

[84] A. Stadel, J. Eboli, A. Ryberg, J. Mitchell and S. Spatari, "Intelligent Sustainable Design: Integration of Carbon Accounting and Building Information Modeling," Journal of Professional Issues in Engineering Education and Practice, vol. 137, pp. $51-54,2011$

[85] K. Hiyama, S. Kato, M. Kubota and J. Zhang, "A new method for reusing building information models of pastprojects to optimize the default configuration for performance simulations," Energy and Buldings, vol. 73, pp. 83-91, 2014.

[86] K.-d. Wong and Q. Fan, "Building information modelling (BIM) for sustainable building design," Facilities, vol. 31, no. 3/4, pp. 138-157, 2013.

[87] P. Sanguinetti, S. Abdelmohsen, J. Lee, J. Lee, H. Sheward and C. Eastman, "General system architecture for BIM: An integrated approach for design and analysis," Advanced Engineering Informatics, vol. 26, pp. 317-333, 2012.

[88] E. Curry, J. O'Donnell, E. Corry, S. Hasan, M. Keane and S. O'Riain, "Linking building data in the cloud: Integrating cross-domain building data," Advanced Engineering Informatics, vol. 27, pp. 206-219, 2013.

[89] A. Cemesova, C. Hopfe and Y. Rezgui, "PassivBIM-a new approach for low energy simulation using BIM," in Conference of Product and Process Modelling (ECPPM), Reykjavik, Iceland, 2012.

[90] P. Geyer, "Systems modelling for sustainable building design," Advanced Engineering Informatics, vol. 26, pp. 656-668, 2012.

[91] I. Kovacic, L. Oberwinter, C. Muller and C. Achammer, "The "BIM-sustain" experiment - simulation of BIM-supported multi-disciplinary design," Visualization in Engineering, vol. 1, no. 1, pp. 1-11, 2013.

[92] Y. Yuan and J. Yuan, "The theory and framework of integration design of building consumption efficiency based on BIM," Automation in Construction, vol. 15, pp. 5323-5327, 2011

[93] B. Welle, J. Haymaker and Z. Rogers, "ThermalOpt: A methodology for automated BIM-based multidisciplinary thermal simulation for use in optimization environments," Building Simulation, vol. 4, no. 4, pp. 293-313, December 2011.

[94] K.-U. Ahn, Y.-J. Kim, C.-S. Park, I. Kim and K. Lee, "BIM interface for full vs, semi-automated building energy simulation," Energy and Buildings, vol. 68, pp. 671678,2014

[95] A. Schlueter and F. Thesseling, "Building information model based energy/exergy performance assessment in early design stages," Automation in Construction, vol. 18, pp. 153-163, 2009

[96] F. Jalaei and A. Jrade, "Integrating BIM with Green Building Certification System, Energy Analysis and Cost Estimating Tools to Conceptually Design Sustainable Buildings," in Construction Research Congress, Atlanta, Georgia, USA, 2014

[97] W. Yan, M. Clayton, J. Haberl, W. Jeong and J. Kim, "Interfacing BIM with Building Thermal and Daylighting Modelling," in Proceedings of BS2013, Chambery, France, 2013.

[98] M. Eguaras-Martinez, M. Vidaurre-Arbizu and C. Martin-Gomez, "Simulation and evaluation of Building Information Modeling in a real pilot site," Applied Energy, vol. 114, pp. 475-484, 2014

[99] M. Nour, O. Hosny and A. Elhakeem, "A BIM based Energy and Lifecycle Cost Analysis/Optimization Approach," International Journal of Engineering Research and Applications, vol. 2, no. 6, pp. 411-418, November-December 2012

[100] P. Sanguinetti, S. Abdelmohsen, J. Lee, H. Sheward and C. Eastman, "Genera system architecture for BIM: An integrated approach for design and analysis," system architecture for BIM: An integrated approach for design
Advanced Engineering Informatics, vol. 26, pp. 317-333, 2012.

[101] S. Azhar, W. Carlton, D. Olsen and I. Ahman, "Building information modeling for sustainable design and LEED ${ }^{\circledR}$ rating analysis," Automation in Construction, vol. 20 , pp. 217-224, 2011

[102] S. Roh, S. Tae and S. Shin, "Development of building materials embodied greenhouse gases assessment criteria and system (BEGAS) in the newly revised Korea Green Building Certification System (G-SEED)," Renewable and Sustainable Energy Reviews, vol. 35, pp. 410-421, 2014.

[103] T. Beach, T. Kasim, H. Li, N. Nisbet and Y. Rezgui, "Towards and automated compliance checking in the construction industry," in 24th International Conference DEXA, Prague, Czech Republic, 2013.

[104] J. K.-W. Wong and K.-L. Kuan, "Implementing 'BEAM Plus' for BIM-based sustainability analysis," Automation in Construction, pp. 163-175, 2014.

[105] M. Gonzalez and J. Navarro, "Assessment of the decrease of $\mathrm{CO} 2$ emissions in the construction field through the selection of materials: Practical case study of three houses of low environmental impact," Building and Environment, vol. 41, pp. 902909, 2006.

[106] L. Ding, Y. Zhou and B. Akinci, "Building Information Modeling (BIM) application framework: The process of expanding from 3D to computable $\mathrm{nD}$," Automation in Construction, vol. 46, pp. 82-93, 2014.
C.

[107] M. Memarzadeh and M. Golparvar-Fard, "Monitoring and Visualization of Building Construction Embodied Carbon Footprint Using DnAR - N-dimensional Augmented Reality Models," in Construction Research Congress, West Lafayette, Indiana, United States, 2012

[108] Y. Schwartz, S. Eleftheriadis, R. Raslan and D. Mumovic, "Semantically enriched BIM Life Cycle Assessment to enhance Buildings' Environmental Performance," in CIBSE Technical Symposium, Edinburgh, UK, 2016.

[109] J. Anderson, G. Wulfhorst and W. Lang, "Energy analysis of the built environmentA review and outlook," Renewable and Sustainable Energy Reviews, vol. 44, pp. 149-158, 2015

[110] L.-S. Wang, P. Ma, E. Hu, D. Giza-Sisson, G. Mueller and N. Guo, "A study of building envelope and thermal mass requirements for achieving thermal autonomy in an office building," Energy and Buildings, vol. 78, pp. 79-88, 2014.
[111] J. Hacker, T. De Saulles, A. Minson and M. Holmes, "Embodied and operational carbon dioxide emissions from housing: A case study on the effects of thermal mas and climate change," Energy and Buildings, vol. 40, pp. 375-384, 2008.

[112] C. Kendrick, R. Ogden, X. Wang and B. Baiche, "Thermal mass in new build UK housing: A comparison of structural systems in a future weather scenario," Energy and Buildings, vol. 48, pp. 40-49, 2012.

[113] H. Wang and Q. Chen, "A semi-empirical model for studying the impact of thermal mass and cost-return analysis on mixed-mode ventilation in office buildings," Energy and Buildings, vol. 67, pp. 267-274, 2013.

[114] A. Dodoo, L. Gustavsson and R. Sathre, "Effect of thermal mass on life cycle primary energy balances of a concrete- and a wood-frame building," Applied Energy, vol. 92 , pp. 462-472, 2012

[115] A. Akbarnezhad, K. Ong and L. Chandra, "Economic and environmental assessment of deconstruction strategies using building information modeling," Automation in Construction, vol. 37, pp. 131-144, 2014.

[116] D. Ness, J. Swift, D. Ranasinghe, K. Xing and V. Soebarto, "Smart steel: new paradigms for the reuse of steel enabled by digital tracking and modelling," Journal of Cleaner Production, pp. 1-12, 2014.

[117] CabinetOffice, "Government Construction Strategy," HMSO , London, UK, 2011.

[118] H.-L. Chi, X. Wang and Y. Jiao, "BIM-Enabled Structural Design: Impacts and Future Developments in Structural Modelling, Analysis and Optimisation Processes, Archives of Computational Methods in Engineering, vol. 22, no. 1, pp. 135-151, 2015.

[119] S. Xa, K. Liu and L. Tang, "Cost Estimation in Building Information Model," in International Conference on Construction and Real Estate Management, Karlsruhe, Germany, 2013.

[120] R. Silva and H. Jayasena, "The need for an integrated cost modelling framework for Building Information Modelling," in The Second World Symposium, Colombo, Sri Lanka, 2013.

[121] A. Monteiro and J. Martins, "A survey on modeling guidelines for quantity takeofforiented BIM-based design," Automation in Construction, vol. 35, pp. 238-253, 2013

[122] M. Zhiliang, W. Zhenhua, S. Wu and L. Zhe, "Application and extension of the IFC standard in construction cost estimating for tendering in China," Automation in Construction, vol. 20, pp. 196-204, 2011.

[123] A. Oti, W. Tizani and A. JalyZada, "A BIM Extension For Sustainability Appraisal Of Conceptual Structural Design Of Steel-Framed Buildings," Computing in Civil and Building Engineering, pp. 219-226, 2014

[124] M. Heinisuo, M. Laasonenand and J. Haapio, "BIM based manufacturing cost estimation of building products," Cork, Republic of Ireland, 2010.

[125] N. Ali, M. Sellami, A.-F. Cutting-Decelle and J.-C. Mangin, "Multi-stage productio cost optimization of semi-rigid steel frames using genetic algorithms," Engineering Structures, vol. 31, pp. 2766-2778, 2009

[126] F. Flager, B. Welle, P. Bansal, G. Soremekun and J. Haymaker, "Multidisciplinar process integration and design optimization of a classroom building," Journal of Information Technology in Construction, vol. 14, pp. 595-612, 2009.

[127] S.-K. Lee, K.-R. Kim and J.-H. Yu, "IM and ontology-based approach for building cost estimation," Automation in Construction, vol. 41, pp. 96-105, 2014.

[128] N. Nawari, "Automating Codes Conformance in Structural Domain," Computing in Civil Engineering, pp. 569-577, 2011

[129] H. Luo and P. Gong, "A BIM-based Code Compliance Checking Process of Deep Foundation Construction Plans," Journal of Intelligent \& Robotic Systems, 2014.

[130] D. Huston, D. Burns and M. Dewoolkar, "Integration of Automated and Robotic Systems with BIM for Comprehensive Structural Assessment," Boston, Massachusetts, United States, 2014.

[131] Z. Hu and J. Zhang, "BIM- and 4D-based integrated solution of analysis and management for conflicts and structural safety problems during construction: 2 Development and site trials," Automation in Construction, vol. 20, pp. 167-180, 2011.

[132] W. Liu, H. Guo, H. Li and Y. Li, "Using BIM to Improve the Design and Construction of Bridge Projects: A case study of a Long-span Steel-box Arch Bridge Project," International Journal of Advanced Robotic Systems, vol. 11, no. 125, pp. 1Project," I1, 2014.

[133] Y. Cho and S. Lee, "Reinforcement Placement in a Concrete Slab Object Using Structural Building Information Modeling," Computer-Aided Civil and Infrastructure Engineering, vol. 29, pp. 47-59, 2014

[134] S. Song, J. Yang and N. Kim, "Development of a BIM-based structural framework optimization and simulation," Computers in Industry, vol. 63, pp. 895-912, 2012.

[135] J. Tulke, M. Nour and K. Beucke, "A dynamic framework for construction scheduling based on BIM using IFC," in Proceedings of the 17th IABSE Congress, Chicago, USA, 2008

[136] J. Tulke and J. Hanff, "4D construction sequence planning - new process and data model," in Proceedings of the CIBW78 24th International Conference on Information Technology in Construction, Maribor, Slovenia, 2007.

[137] S.-I. Lee and J.-S. C. Y. Bae, "Efficiency analysis of Set-based Design with structural building information modeling," Automation in Construction, vol. 23, pp. 20-32, 2012

[138] X. Shi, "Performance-based and performance-driven architectural design and optimization," Frontiers of Architecture and Civil Engineering in China, vol. 4, no. 4, pp. 512-518, 2010.

[139] S. Attia, M. Hamdy, W. O'Brien and S. Carlucci, "Assessing gaps and needs for integrating building performance optimization tools in net zero energy buildings design," Energy and Buildings, vol. 60, pp. 110-124, 2013.

[140] S. Eleftheriadis, D. Mumovic, P. Greening and A. Chronis, "BIM Enabled Optimisation Framework for Environmentally Responsible and Structurally Efficien Design Systems," Oulu, Finland, 2015.

[141] M. Rafiq and M. Rustell, "Building Information Modeling Steered by Evolutionary Computing," Journal of Computing in Civil Engineering, vol. 28, no. 4, 2014. 
[142] A. Porwal and K. Hewage, "Building Information Modeling-Based Analysis to Minimize Waste Rate of Structural Reinforcement," Journal of Construction Engineering and Management, vol. 138, pp. 943-954, 2012.

[143] V. Faghini, K. Reinschmidt and J. Kang, "Construction scheduling using Genetic Algorithm based on Building Information Model," Expert Systems with Applications, vol. 41, pp. $7565-7578,2014$
[144] S. Eleftheriadis, D. Mumovic, P. Duffour and P. Greening, "Multi-performance optimisation framework for the selection of structural alternatives based on sustainable qualities," in SEMC, Cape Town, South Africa, 2016. 